Review article

\title{
TOR and SnRK1 signaling pathways in plant response to abiotic stresses: Do they always act according to the "yin-yang" model?
}

\author{
Marianela Rodriguez $^{\mathrm{a}, \mathrm{b}, *}$, Rodrigo Parola ${ }^{\mathrm{a}, \mathrm{b}}$, Sofia Andreola ${ }^{\mathrm{a}, \mathrm{b}}$, Cintia Pereyra ${ }^{\mathrm{c}}$, \\ Giselle Martínez-Noël ${ }^{c}$ \\ a Instituto de Fisiología y Recursos Genéticos Vegetales (IFRGV), Centro de Investigaciones Agropecuarias (CIAP), Instituto Nacional de Tecnología Agropecuaria (INTA), \\ Camino 60 Cuadras km 5.5, X5020ICA, Córdoba, Argentina \\ ${ }^{\mathrm{b}}$ Unidad de Estudios Agropecuarios (UDEA- CONICET), Camino 60 Cuadras km 5.5 X5020ICA, Córdoba, Argentina \\ ${ }^{\mathrm{c}}$ Instituto de Investigaciones en Biodiversidad y Biotecnología (INBIOTEC-CONICET), y Fundación para Investigaciones Biológicas Aplicadas (FIBA), Vieytes 3103, 7600, \\ Mar del Plata, Argentina
}

\section{A R T I C L E I N F O}

\section{Keywords:}

Abiotic stresses

Energy sensors

Metabolic signaling

Plant stress response

SnRK1

TOR

\begin{abstract}
A B S T R A C T
Plants are sessile photo-autotrophic organisms continuously exposed to a variety of environmental stresses. Monitoring the sugar level and energy status is essential, since this knowledge allows the integration of external and internal cues required for plant physiological and developmental plasticity. Most abiotic stresses induce severe metabolic alterations and entail a great energy cost, restricting plant growth and producing important crop losses. Therefore, balancing energy requirements with supplies is a major challenge for plants under unfavorable conditions. The conserved kinases target of rapamycin (TOR) and sucrose-non-fermenting-related protein kinase-1 (SnRK1) play central roles during plant growth and development, and in response to environmental stresses; these kinases affect cellular processes and metabolic reprogramming, which has physiological and phenotypic consequences. The "yin-yang" model postulates that TOR and SnRK1 act in opposite ways in the regulation of metabolic-driven processes. In this review, we describe and discuss the current knowledge about the complex and intricate regulation of TOR and SnRK1 under abiotic stresses. We especially focus on the physiological perspective that, under certain circumstances during the plant stress response, the TOR and SnRK1 kinases could be modulated differently from what is postulated by the "yin-yang" concept.
\end{abstract}

\section{Introduction}

One of the greatest global challenges today is satisfying the needs of a growing population in an environmentally and socially sustainable manner [1]. The dependence on plants for human food, animal feed, and fuel poses major challenges to our agricultural production systems, including climate change, limitation of arable land, desertification, environmental degradation, changes in water quality and quantity, and increased protein demands [2-4]. Therefore, the need for agricultural adaptation is clear, and advances in plant research must provide new technologies and knowledge to face these issues [3,5].

As sessile organisms, plants are subjected to a diverse array of abiotic stressors and respond with metabolic changes that negatively impact their growth and development [6]. Plants adjust their metabolism under stresses through transient, sustained, early/late and/or tissue specific responses $[7,8]$. One of the changes induced by unfavorable conditions is the alteration of sugar concentration. For example, low irradiance, heat or hypoxia due to submergence results in sugar starvation [9-11]. On the other hand, cold [12], drought, salt and nutrient deficiency induce sucrose (Suc) accumulation [13-15]. These alterations in sugar levels might be caused by the under-utilization of carbon (C), which in turn is due to a growth rate decrease or sinklimited condition, triggering adaptive responses for stress survival $[6,12,14,16]$. Furthermore, carbohydrate allocation at cellular, sub-

Abbreviations: ABA, abscisic acid; AUX, auxin; BR, brassinosteroid; C, carbon; ET, ethylene; FUS3, FUSCA 3; GA, gibberelic acid; Glc, glucose; JA, jasmonic acid; LST8, lethal with SEC13 protein 8; N, nitrogen; RFO, raffinose family oligosacharide; RAPTOR, regulatory-associated protein of TOR; RPS6, ribosomal protein S6; S6K, ribosomal protein S6 kinase; ROS, reactive oxygen species; SnRK1, sucrose non-fermenting-related kinase 1; Suc, sucrose; TOR, target of rapamycin; Tre6P, trehalose-6-phosphate; TPSTrehalose, phosphate synthase; WT, wild type

* Corresponding author at: Instituto de Fisiología y Recursos Genéticos Vegetales (IFRGV), Centro de Investigaciones Agropecuarias (CIAP), Instituto Nacional de Tecnología Agropecuaria (INTA), Camino 60 Cuadras km 5.5, X5020ICA, Córdoba, Argentina.

E-mail addresses: rodriguez.marianela@inta.gob.ar (M. Rodriguez), parola.rodrigo@inta.gob.ar (R. Parola), andreolasofia@gmail.com (S. Andreola), cintiampereyra@gmail.com (C. Pereyra),gnoel@inbiotec-conicet.gob.ar (G. Martínez-Noël). 
cellular and tissue levels has been shown to be involved in stress-induced reprogramming of metabolism [17-20]. For instance, osmotic stress causes kernel abortion in maize, which is due not to a lack of carbohydrate reserves, but to the inability to use these energy sources [14]. In this context, the effect could be related to sugar acting as signal molecules. It is well known that sugars promote changes in gene expression and protein activity modulation [21-26]. Sugar sensing and signaling pathways during plant development and in response to environmental conditions have been described end extensively reviewed [21,22,26-32].

Sugar signals can be translated by protein kinases related to energy metabolism. In this regard, TOR (Target of rapamycin) kinase complex is an important metabolic and energy sensor that regulates cellular homeostasis in balance with the SnRK1 (Sucrose non-fermenting-related kinase 1) kinase [33,34]. TOR integrates external and internal signals and transduces them to growth and developmental programs, and is also involved in responses to environmental stresses [34-38]. On the other hand, the plant SnRK1 triggers activation of catabolism and repression of energy-consuming anabolic (biosynthetic) reactions when energy supplies are limited [39]. Thus, TOR and SnRK1 form the core of a complex and intricate regulatory network to coordinate metabolic activities. It is commonly accepted that TOR and SnRK1 interact closely and act in opposite ways in the regulation of nutrient-driven processes ("yin-yang" model) [33,40,41]. Accordingly, under feast conditions TOR is active whereas SnRK1 is inhibited, promoting anabolism and repressing catabolism [33,42]. Conversely, under sugar and energy starvation SnRK1 is activated and TOR is inhibited, inducing stress responses [33,42]. However, as mentioned above, several abiotic stresses induce soluble sugar accumulation but at the same time activate energy-deficient sensors $[11,39,43,44]$. Thus, how are the metabolic- and energy-signals decoded under stress conditions? Various reports indicate that both SnRK1 and TOR overexpressors were more tolerant to abiotic stress than wild-type (WT) plants $[45,46]$. Such discrepancies could be due to differences related to the characteristics of the abiotic stress (stressor nature, duration and intensity of the stress) and/or to the affected plant (tissue type, heterotrophic or autotrophic, development stage, plant species). Table 1 summarizes the huge diversity of experimental systems used to study TOR and SnRK1 signaling pathways under abiotic stress (research works not including abiotic stresses were excluded from this table).

In this review, we analyze and discuss the present status of knowledge about the regulation of TOR and SnRK1 networks under unfavorable conditions and their roles in the plant stress response in the context of the "yin-yang" model. Firstly, a brief introduction about TOR and SnRK1 is provided. Then, the upstream and downstream regulation of both kinases during abiotic stress is described.

\section{TOR kinase}

TOR is a highly conserved protein in all eukaryotes, from unicellular to multicellular organisms such as humans, and it is essential for life. TOR kinase positively controls crucial biological anabolic processes, such as cell cycle, ribosome biogenesis, protein synthesis, transcription, nutrient transport, $\mathrm{C}$ and nitrogen $(\mathrm{N})$ utilization, cell wall changes, chloroplast formation, photosynthesis, and negatively controls autophagy $[34,36,42,47,48]$. In plants, huge advances have been made regarding TOR signaling in the last decade, but many aspects of its functions and mechanisms are still unknown, especially under stress conditions. Given the great importance of TOR signaling, the null tor mutants are non-viable [35]. Besides, the mammalian TOR inhibitor rapamycin is only partially effective in Arabidopsis thaliana, and this has delayed the study of TOR signaling in plants. The generation of inducible tor RNAi lines and the development of specific kinase TOR activity inhibitors (such as PP242, Torin and AZD-8055) allowed the discovery of TOR functions in plants [49,50]. The main problem to advance in the field was due to the difficulty in measuring TOR kinase activity in vivo, which has been partially overcome with the use of specific antibodies that recognized the phosphorylation of TOR-target proteins, such as $40 \mathrm{~S}$ ribosomal S6 protein kinase (S6K) and ribosomal protein S6 (RPS6) [42,51].

As its mammalian and yeast counterpart, plant TOR is a multidomain protein and belongs to the phosphatidylinositol 3-kinase-related lipid kinase family [35,52]. TOR kinase is associated with RAPTOR (Regulatory-Associated Protein of TOR) and LST8 (lethal with SEC13 protein 8) partners to form the TOR complex 1 (TORC1). RAPTOR interacts with the N-terminal of TOR and promotes the recruitment of the kinase substrates such as S6K1 [53]. Moreover, LST8 protein binds to the C-terminal kinase domain of TOR and regulates substrate selectivity and consequently TORC activity [54]. Recently, Aylett et al. [55] resolved the first high definition structure of mTORC1 and showed that the complex adopts a dimeric architecture with a diamond form. The TOR kinase domains are in the center of the rhomb, while RAPTOR and LST8 proteins form the peripheral parts, being the top of the longer and shorter axes of the lozenge, respectively. On the contrary, the TOR structure of plants has still not been determined.

\subsection{The fine-tuning of the TOR kinase by upstream effectors}

It is commonly accepted the TORC1 complex is activated by nutrients, whereas it is inhibited by sugar starvation and diverse stresses in both plants and animals [42,56-58]. In plants, glucose (Glc) and Suc activate TOR signaling, even though the molecular mechanisms are still unknown. Induction of TOR kinase by Glc regulates central and secondary metabolism, cell cycle, transcription, signaling, transport and protein folding through transcriptional reprogramming of key genes [49] (Fig. 1). Strikingly, several upstream regulators of TOR signaling in yeast and mammals, such as the kinase TSC complex, Rheb G-protein, RAGs or Akt kinase, are not conserved in land plants [59,60]. The absence of homologous proteins may be the main reason why the upstream regulation of TOR is poorly understood in plants. Xiong and Sheen [58] reported that amino acids also activate plant TOR signalling through S6K phosphorylation; however, those results are still unpublished. Recently, TOR was found to partially mediate plant growth and development by inorganic nutrients (N, P and S) [61]. Dong et al. [61] suggested that plants sense cysteine precursors rather the cysteine itself, with TOR and GCN2 kinase being the sensors of $\mathrm{S}$ and $\mathrm{C} / \mathrm{N}$ availability, respectively. TOR transduces the $S$ limitation through the modulation of glucose metabolism. This mechanism allows plants to coordinate the fluxes of $\mathrm{C}, \mathrm{N}$ and $\mathrm{S}$ for efficient cysteine biosynthesis. Moreover, the GTPase ROP2 is a direct upstream effector that activates TOR in plants in response to auxin [62] (see section 2.3 for further details).

Another specific regulation of TOR in photosynthetic organisms is the direct activation of the kinase by light, which causes induction of WUSCHEL transcription factor gene expression and ultimately activates the stem cells in shoot apical meristem [63]. In addition, it was reported that light activates TOR kinase through auxin (AUX) signaling along with sugars, to promote cell division in the shoot apex [64] (see section 2.3). The fact that TOR integrates light and metabolic signals may be key in plants for the shift from skotomorphogenesis to photomorphogenesis [65]. Enganti et al. [66] described that RPS6 phosphorylation is regulated by the light-dark cycle, peaking during the day. Recently, Li et al. [67] proposed a model for TOR regulation by circadian clock. The authors suggested that the circadian components Pseudo Response Regulators (PRRs) control root meristem through TOR signaling. PRRs repress the RNA-binding protein TZF1 (Tandem Zinc Finger 1), which directly binds to TOR transcripts, thus negatively affecting their stability.

The tight regulation of TORC1 by SnRKs kinases is described in sections 2.3 and 4 . 
Table 1

TOR and SnRK1 under different abiotic stress conditions.

\begin{tabular}{|c|c|c|c|c|c|}
\hline $\begin{array}{l}\text { Signaling } \\
\text { pathway }\end{array}$ & $\begin{array}{l}\text { Stress } \\
\text { condition }\end{array}$ & Tissue & Development stage & Plant species & References \\
\hline \multirow[t]{15}{*}{ TOR } & \multirow[t]{3}{*}{ Cold } & Whole plant & Seedling & Arabidopsis thaliana & {$[66,93]$} \\
\hline & & Shoot & Reproductive & Arabidopsis thaliana & [94] \\
\hline & & Flower bud, leaf & $\begin{array}{l}\text { Reproductive and post- } \\
\text { reproductive }\end{array}$ & Prunus pérsica & [177] \\
\hline & \multirow[t]{3}{*}{ Drought } & Seed & Germination & Arabidopsis thaliana & [178] \\
\hline & & Shoot, root & Reproductive & Oryza sativa & {$[46]$} \\
\hline & & Flower bud, leaf & $\begin{array}{l}\text { Reproductive and post- } \\
\text { reproductive }\end{array}$ & Prunus pérsica & [177] \\
\hline & \multirow[t]{2}{*}{ Salt } & Seed & Germination & Arabidopsis thaliana & [178] \\
\hline & & Flower Bud, leaf & $\begin{array}{l}\text { Reproductive and post- } \\
\text { reproductive }\end{array}$ & Prunus pérsica & [177] \\
\hline & \multirow[t]{2}{*}{ Osmotic } & Whole plant & Seedling & Arabidopsis thaliana & {$[90]$} \\
\hline & & Leaf & Seedling & Arabidopsis thaliana & {$[53]$} \\
\hline & Hypoxia & Shoot, root & Seedling & Arabidopsis thaliana & [79] \\
\hline & Darkness and starvation & $\begin{array}{l}\text { Shoot, root, bud, flower, } \\
\text { mesophyll cell }\end{array}$ & $\begin{array}{l}\text { Vegetative, reproductive, } \\
\text { senescence }\end{array}$ & Arabidopsis thaliana & [69] \\
\hline & \multirow[t]{3}{*}{ Heat } & Whole plant & Seedling & Arabidopsis thaliana & {$[66]$} \\
\hline & & Leaf & NA & Lolium perenne & [179] \\
\hline & & Flower bud, leaf & $\begin{array}{l}\text { Reproductive and post- } \\
\text { reproductive }\end{array}$ & Prunus pérsica & {$[177]$} \\
\hline \multirow[t]{2}{*}{ TOR and SnRK1 } & Iron deficiency & Shoot, whole plant & Vegetative & Glycine $\max$ & {$[180]$} \\
\hline & $\begin{array}{l}\text { Salt, osmotic, oxidative, ER, } \\
\text { starvation }\end{array}$ & Whole plant & Seedling & Arabidopsis thaliana & {$[181]$} \\
\hline \multirow[t]{25}{*}{ SnRK1 } & \multirow[t]{3}{*}{ Cold } & Source and sink leaf, root & Vegetative & Arabidopsis thaliana & [8] \\
\hline & & Whole plant & Seedling & Arabidopsis thaliana & [12] \\
\hline & & Root, stem, leaf, flower, fruit & Reproductive & $\begin{array}{l}\text { Solanum habrochaites, } \\
\text { Solanum pennelli, } \\
\text { Solanum lycopersicum }\end{array}$ & [141] \\
\hline & \multirow[t]{3}{*}{ Drought } & Whole plant & Seedling & Arabidopsis thaliana & {$[118,182]$} \\
\hline & & $\begin{array}{l}\text { Ear, Spikelet, floret, fully } \\
\text { expanded leaf }\end{array}$ & Reproductive & Zea mays & {$[13,16,183]$} \\
\hline & & Root, stem, leaf, flower, fruit & Reproductive & $\begin{array}{l}\text { Solanum habrochaites, } \\
\text { Solanum pennelli, } \\
\text { Solanum lycopersicum }\end{array}$ & {$[141]$} \\
\hline & \multirow[t]{3}{*}{ Salt } & Mesophyll cell, whole plant & Vegetative, seedling & Arabidopsis thaliana & [137] \\
\hline & & Source-sink leaf, root & Vegetative & Arabidopsis thaliana & {$[8]$} \\
\hline & & $\begin{array}{l}\text { Young, middle-lowest leaf, shoot, } \\
\text { tuber }\end{array}$ & Vegetative & Solanum tuberosum & [184] \\
\hline & \multirow[t]{3}{*}{ Osmotic } & Whole plant, mesophyll cell & Seedling & Arabidopsis thaliana & [121] \\
\hline & & Source and sink leaf, roots & Vegetative & Arabidopsis thaliana & {$[8]$} \\
\hline & & Leaf, root, hypocotyl & Seedling & $\begin{array}{l}\text { Phaseolus } \\
\text { vulgaris }\end{array}$ & [162] \\
\hline & \multirow[t]{3}{*}{ Flooding } & Whole plant, mesophyll cell & Seedling & Arabidopsis thaliana & {$[137,160,161]$} \\
\hline & & Mesophyll cell, whole plant, leaf & Seedling, senescence & $\begin{array}{l}\text { Oryza sativa, Arabidopsis } \\
\text { thaliana }\end{array}$ & [45] \\
\hline & & Whole plant, mesophyll cell & Seedling & Oryza sativa & [119] \\
\hline & Hypoxia & Leaf, mesophyll cell & Vegetative, reproductive & Arabidopsis thaliana & [39] \\
\hline & \multirow[t]{4}{*}{ Darkness } & $\begin{array}{l}\text { Whole plant, root, shoot, } \\
\text { mesophyll cell }\end{array}$ & Seedling, vegetative & Arabidopsis thaliana & {$[121,137,185]$} \\
\hline & & Leaf, mesophyll cell & Vegetative, reproductive & Arabidopsis thaliana & {$[10,39,186,187]$} \\
\hline & & Leaf & Senescence & Arabidopsis thaliana & [138] \\
\hline & & Leaf & Vegetative & Haberlea rhodopensis & [188] \\
\hline & \multirow{5}{*}{ Nutrient deficiency } & Whole plant & Seedling & Arabidopsis thaliana & [182] \\
\hline & & Whole plant, root & Germination, seedling & Arabidopsis thaliana & [189] \\
\hline & & Leaf, root, mesophyll cells & NA & Arabidopsis thaliana & [190] \\
\hline & & Kernel & Reproductive & Zea mays & {$[191]$} \\
\hline & & Fruit, pod, seed & Reproductive & $\begin{array}{l}\text { Phaseolus } \\
\text { vulgaris }\end{array}$ & {$[192,193]$} \\
\hline
\end{tabular}

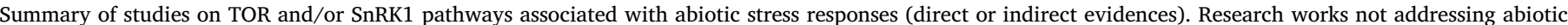
stresses were not included in this table. Tissue, developmental stage and plant species are indicated. NA: not available information.

\subsection{Downstream targets of TOR kinase}

The most widely studied and conserved TOR target is S6K, which in turn phosphorylates RPS6 and finally might promote protein translation (Fig. 1). Arabidopsis has two S6K homologues, S6K1 and S6K2, which are phosphorylated on Thr-449 and Thr-455, respectively [51]. S6K1 was found to bind to RAPTOR protein in TORC1 [53]. In addition to RPS6, the axis TOR-S6K1 phosphorylates eIF3h (eukaryotic Initiation Factor 3, subunit $\mathrm{H}$ ) promoting the translation reinitiation of upstream reading frame (uORFs)-mRNAs [68]. It has been recently described that
MRF1 (MA3 DOMAIN-CONTAINING TRANSLATION REGULATORY FACTOR1), which modulates translation under stress conditions, is also a target of the TOR-S6K pathway [69]. In addition, TOR signaling regulates protein translation and other processes through the direct phosphorylation of TAP46, a regulatory subunit of PP2A and a positive effector of TOR [70]. Overexpression of TAP46 in Arabidopsis increased the expression of genes involved in ribosome biogenesis, nitrogen assimilation, and lignin biosynthesis, and decreased those related to autophagy [71]. In plants, it was suggested that TAP46 acts as an inhibitor of PP2A activity. However, the exact effects on phosphatase modulation 


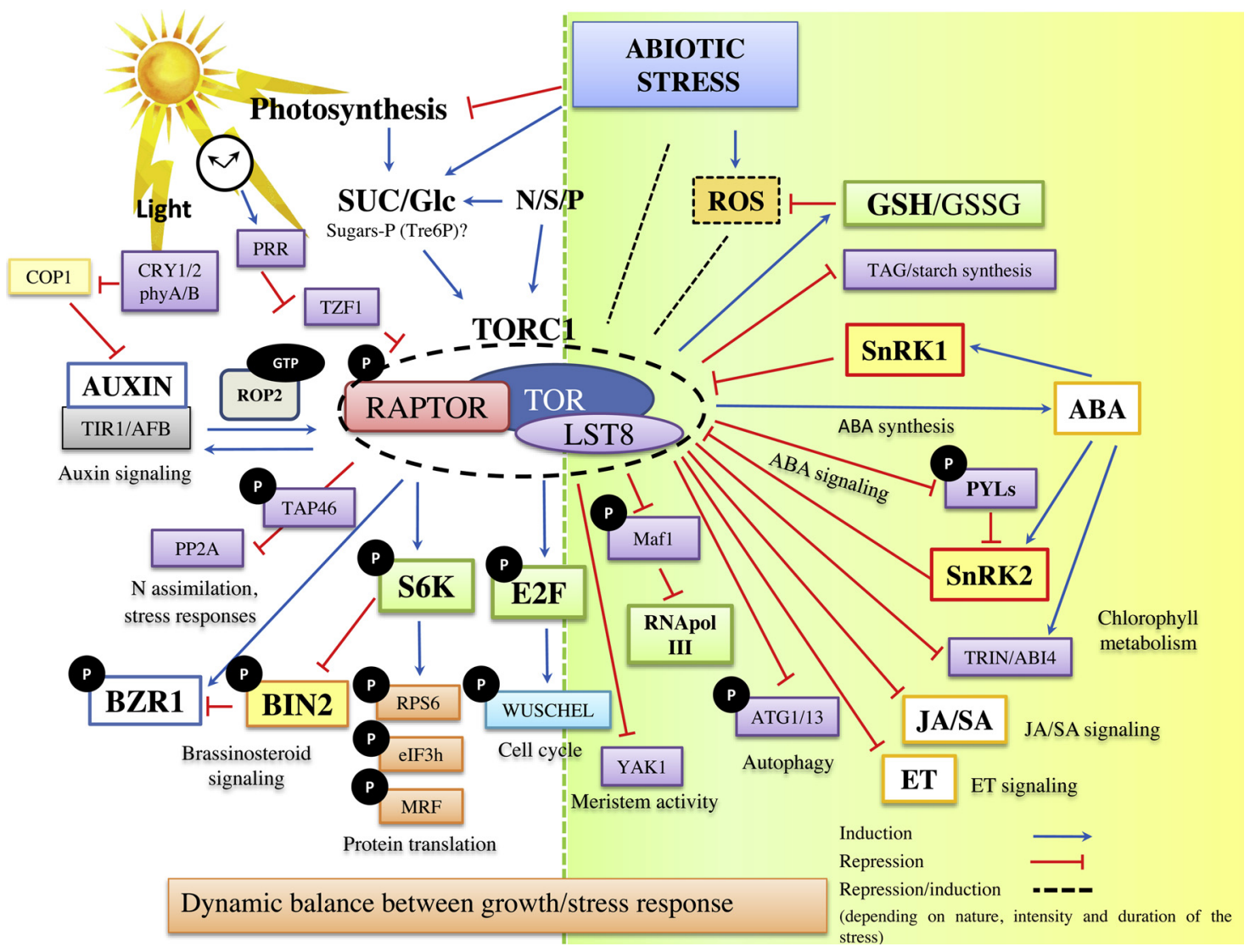

Fig. 1. Schematic representation of TOR signaling in plants under abiotic stress. TOR kinase is activated in plants by light, sugars and inorganic nutrients such as $\mathrm{S}$, $\mathrm{N}$ and P. The light pathway involves the growth hormone auxin and the ROP2-GTPase. In addition, circadian clock also regulates TOR signaling. Active TOR kinase generates a plethora of responses that induce anabolism and repression of catabolism, and therefore promotes plant growth and development. Under favorable conditions, TOR promotes protein transduction and cell cycle progression through the activation the S6K and E2F axes, respectively. In turn, S6K phosphorylates several important protein targets such as the S6 protein of the 40S ribosomal subunit (RPS6) and the component of the eukaryotic translation initiation factor 3 complex eIF3h. TOR also induces protein synthesis by the release of the inhibition of RNApol III by its Maf1 repressor. TOR stimulates growth through the phosphorylation of TAP46, a regulatory subunit of PP2A. Moreover, TOR promotes meristem activity and size (cell proliferation), repressing YAK1 kinase. In plants, TOR also stimulates chlorophyll and chloroplast biosynthesis through the destabilization of the negative regulator TRIN/ABI4. Besides, TOR induces the signaling of growth-activating hormones, AUX and BR. On the other hand, TOR inhibits autophagy, lipid/starch synthesis and signaling of the stress hormones. TOR inactivates ABA signaling by phosphorylation of the ABA PYL receptors. During abiotic stress conditions, a gradient of plant responses may be triggered, depending on the duration, intensity and nature of the stressor. Following the "yin-yang" model, TOR kinase is inactivated by SnRKs, which are induced by ABA under unfavorable conditions, releasing the autophagy repression and the stress hormone signaling inhibition via TOR (repression of ABA, ET, JA/SA signaling). However, TOR is necessary for the synthesis of ABA and glutathione; hence, active TOR might be required in the response to stress. Moreover, whether ROS has an inducing or inhibiting effect on TOR kinase in plants is unclear and would be related to the ROS levels generated during the stress or their subcellular localization. Red and blue solid arrows show activation or inhibition, respectively, and dashed arrows point to a possible induction or inhibition, depending on the nature, intensity and/or duration of the abiotic stress. See section 2 and 4 for further details.

remain to be investigated [71]. Another target of TOR signaling is Maf1, a global repressor of RNA polymerase III and therefore of the protein translation and cell growth. Maf1 activity is inhibited by phosphorylation and is activated by TOR kinase inhibitors [72]. Moreover, PP2As dephosphorylate Maf1, causing its activation, and thus acting in an opposite manner to that of TOR kinase. Interestingly, it was suggested that Maf1 is needed for plant survival under stress conditions [72].

Other key downstream targets of TOR signaling are E2F transcription factors, which induce expression of S-phase genes and cell cycle progression [49]. In addition, S6K regulates cell cycle but its effect is influenced by the cellular context. TOR also positively controls chlorophyll metabolism, chloroplast biogenesis and hypocotyl elongation by destabilizing the transcription factor TRIN/ABI4 in the nucleus, being a plant specific downstream effector of TOR signaling [73]. Recently, the new TOR-YAK1 axis was reported in Arabidopsis [74]. Barrada et al. [74] reported that mutants of the YAK1 kinase were resistant to the TOR inhibitor AZD-8055 and, inversely, the overexpressors were hypersensitive. These authors proposed a model in which active TOR inhibits YAK1 kinase, promoting root meristem activity and size increase (cell proliferation instead of differentiation). The strongest evidence comes from the recent paper by Forzani et al. [75] where it is now demonstrated that YAK1 is a direct TOR substrate.

Recently, Van Leene et al. [76] reported the first TOR complex interactome/phosphoproteome, in which they identified several new targets and upstream regulatory proteins. The authors not only confirmed the known role of TOR signalling in diverse processes, such protein synthesis and autophagy, but also discovered novel links. For example, they detected the protein PAH2 (LIPIN1 orthologue) as a direct target of phosphorylation of TOR, linking the kinase with lipid metabolism in plants as it happens in mammals. Interactors of LST8-1 and RAPTOR1B were also found such as THY-1 (thymidylate synthase), which could mean that TOR may regulate the nucleotides synthesis. Interestingly, the work also described 63 new TOR-protein interactions that had not been described before in any organism, such as the targets eIF2B-81/eIF6A (translation initiation factors), MEE29/AT4G0129 (proteins that bind to the $5^{\prime}$ cap of plant mRNAs) and PUX5 (a CDC48 cofactor related to endoplasmic reticulum and Golgi biogenesis). 
Furthermore, the authors identified upstream effectors of TOR complex such as the CCT and TTT complexes (chaperonins) as strong interactors of LST8-1 and RAPTOR1B proteins. Those interactions could contribute to the folding and assembly of the TOR complex. Regarding the stress response, the interaction between RAPTOR1B and the catalytic subunit of the SnRK1 was confirmed (SnRK1.1 and SnRK1.2). Overall, this study provides original and invaluable clues to enhance the knowledge of TOR signaling.

\subsection{How do plants cope with abiotic stresses? TOR signaling and phytohormone}

Plant hormones play critical roles in helping plants cope with abiotic stresses. Hence, their crosstalk with other key pathways, such as TOR signaling, is essential to coordinate growth and plant stress responses [38,77]. Accordingly, Dong et al. [78] described that genes related to the eight phytohormones signaling were differently regulated when TOR activity was inhibited in Arabidopsis. Plant hormones that promote growth, such AUX and brassinosteroids (BR), are positively correlated with TOR signaling. AUXs activate TOR-S6K1 pathway and consequently increase the translation reinitiation of the mRNAs that contain uORFs, such as AUX response factors [68,79]. AUXs activate TOR through the small GTPase ROP2, being a direct kinase upstream effector in plants [62]. TOR also regulates TIR1/AFBs stability (AUX receptor), modulating AUX-dependent cell differentiation/proliferation during adventitious root formation [80]. Recently, it was reported that photoreceptors (CRY and PHY) induce AUX signaling and thus activation of TOR-S6K axis, through the inactivation of the negative regulator COP1 (CONSTITUTIVE PHOTOMORPHOGENESIS 1) in deetiolating Arabidopsis seedlings [81]. In addition, Glc-TOR signaling activates BR pathway through BR-signaling transcription factor BZR1 stabilization, thus promoting plant growth and hypocotyl elongation in darkness [81]. The transcription factor BZR1 balances the growth stimulated by steroid with C availability. Moreover, TOR phosphorylates BIN2, a negative regulator of BR signaling, also stimulating BR signaling [82]. It was reported that BR modulates stress responses; however, the underlying mechanism is still unknown [83,84].

The hormones ethylene (ET), jasmonic acid (JA) and abcisic acid (ABA) are also interconnected with TOR kinase. It was reported that the genes encoding the ET signaling pathway were all up-regulated in the TOR inactivated plants [78]. Moreover, TOR negatively affects JA biosynthesis in Arabidopsis and cotton, but the involved molecular mechanisms have to be investigated [85]. Regarding ABA, a critical phytohormone for plant growth and development under environmental stresses, a reciprocal regulation was demonstrated with TOR signaling. In unstressed situations, TOR phosphorylates ABA receptor PYL and prevents SnRK2 activation by ABA. On the other hand, under stress conditions, ABA inhibits TOR signaling through SnRK2. SnRK2 phosphorylates RAPTOR protein, which causes its dissociation from TORC1 [86]. ABA also stimulates SnRK1 (see section 3.3). Interestingly, it was reported that TOR activity is required for the synthesis of ABA and, therefore, for the efficient development of the defense response to abiotic stresses [87]. The authors demonstrated that ABA levels and expression of ABA synthesis genes were decreased in TOR-inhibited seedlings of Arabidopsis. Another point of crosstalk between ABA and TOR signaling is the TIP41 protein (TAP42 INTERACTING PROTEIN OF $41 \mathrm{kDa}$ ) through the modulation of the TOR target-PP2A [88]. PP2As interact with SnRK2s and, thus, are involved in ABA responses, being either positive or negative regulators, depending on the tissue [89]. It was recently described that TIP41 may regulate PP2A activity via its interaction with the phosphatase catalytic subunit in Arabidopsis. Moreover, TOR signaling is affected in the tip41 mutant, which is more sensitive to TOR inhibitors. Interestingly, TIP41 was induced transiently under long-term exposure to different abiotic stresses and ABA treatment [88].

\subsection{TOR signaling under abiotic stress: is its activity required for stress} response?

It has been proposed that under energy-limiting conditions, TOR signaling is down-regulated in plants and animals ("yin-yang" model) $[34,47]$. However, knowledge about the effect of abiotic stress on TOR signaling in plants is scarce and sometimes apparently contradictory.

One of the first reports on TOR signaling under stress conditions described that S6K1 activity was reduced under osmotic stress in leaves of tobacco transiently expressing the kinase, possibly via TOR pathway [53]. Later, constitutive TOR over-expressing Arabidopsis lines were found to relieve the negative effects of osmotic stress on root growth with respect to the WT control [90]. Nevertheless, this effect may be due to the basal increase of TOR activity rather than to the stress response, since the authors did not compare the same TOR over-expressing line under control and osmotic conditions. Subsequently, several reports described that inducible TOR mutants or WT plants treated with TOR inhibitors behaved as in a stress situation, despite the absence of the stressor $[49,91,92]$. Those plants with a down-regulated TOR signaling showed up-regulation of genes involved in stress responses and autophagy. In agreement with those results, Pu et al. [44] showed that over-expression of TOR repressed autophagy induction during nutrient deprivation and salt and osmotic stress, suggesting that TOR activity down-regulation was needed for the stress response. Interestingly, Bakshi et al. [46] described that TOR overexpression upregulates transcription of multiple stress-response genes in rice. Indeed, Wang et al. [93] described that TOR kinase was inhibited at an early stage of cold stress in Arabidopsis, but after $2 \mathrm{~h}$ of cold treatment TOR activity was restored and even increased at $24 \mathrm{~h}$. In this line, Dong et al. [94] found that TOR-RNAi line was cold-sensitive, which suggests that an active TOR was necessary for cold tolerance. TOR signaling induced by stress were also reported for other eukaryotic organisms [95,96]. Furthermore, TOR signaling was also found to be involved in the defense response to biotic stresses in plants [97-99].

In summary, available information about the role of TOR under abiotic stress conditions is fragmentary and in some cases contradictory. This fact underscores that the role of TOR in abiotic stress responses is highly complex and not straightforward as supposed by the "yin-yang" model. In this regard, different reports have conducted a wide diversity of experiments in terms of tissue and type of stress (Table 1). Each work addresses part of a more complex process but none of them analyzes the complete scenario.

\subsection{Does abiotic stress downregulate TOR signaling in plants?}

As we mentioned above, it is well known that sugar accumulation is observed under several abiotic stresses [7,100,101]. It could be expected that this high availability of photoassimilates results in induction of TOR activity; however, this assumption seems to contradict the "yin-yang" model, which considers that TOR is inhibited under stress situations.

Possible explanations can be proposed to solve this apparent contradiction. One interpretation could be that the TOR kinase is inactivated above a given threshold of sugars. Another possibility is that hexose-to-Suc ratio alteration or a different subcellular localization of sugars and the TOR complex prevent kinase activation. Interestingly, an alternative hypothesis could be that an active TOR kinase is needed for the plant stress response. Accordingly, one of the first proposals related to a possible activation of TOR signaling was made by Yokawa and Baluška [102]. The authors suggested that TOR could be activated by reactive oxygen species (ROS) as an escape behavior to avoid the stress situation (perception of high salt concentration or light by the root). In line with the idea of the requirement of an active TOR during stress, it was reported that TOR is necessary for the synthesis of ABA [87]. It is clear that there is a connection between sugars, TOR and ABA, but the details of those links in mild- or short-term and long-term abiotic stress 
responses are still unknown. Moreover, the specificity of the sugar signaling pathway leading to the induction of TOR has still not been determined. It is important to elucidate whether TOR activation by sugars occurs via a disaccharide or hexose signaling.

Another controversial subject is the effect of ROS on TOR signaling in plants. Unfavorable conditions induce metabolic and signaling ROS generation, which is a stress-specific ROS signature [103]. If detoxifying mechanisms fail and ROS species accumulate in excess, producing an imbalance, ROS become extremely toxic. However, if cells have enough available energy to scavenger ROS and maintain their levels under non-toxic concentrations, the effect of ROS during abiotic stress may be beneficial for the plant. Thus, ROS-antioxidant interaction acts as a metabolic interface for signals derived from metabolism and the environment [104]. In this context, glutathione is one of the major soluble non-enzymatic ROS scavengers [105]. Interestingly, it was described that Glc-TOR axis controls expression of glutathione synthesis genes, leading to the increase of this potent antioxidant in Arabidopsis seedlings [49]. In addition, it was reported that pharmacological inhibition of TOR results in an increase in oxidized glutathione (GSSG) level in Arabidopsis [91]. Recently, Speiser et al. [106] suggested that TOR may be stabilized by oxidizing conditions promoted by stress and thus, be active for the induction of glutathione synthesis to face the adverse condition. Despite the advances in the field of TOR signaling made in the last years, more research is still needed to elucidate and understand the complex TOR function under redox alteration induced by abiotic stress conditions (Fig. 1).

\section{SnRK1 kinase}

SnRKs are part of a family of evolutionary conserved eukaryotic protein kinases [107]. The conserved animal AMPK (AMP-activated kinase), yeast SNF1 (Sucrose non-fermenting1) and plant SnRK1 (SNF1related kinase 1) protein kinases have been characterized [41]. SnRK1 is encoded by three catalytic subunits in Arabidopsis plants: SnRK1.1 (KIN10); SnRK1.2 (KIN11) and SnRK1.3 (KIN12) [39]. The SnRK1 kinases function as hetero-trimeric complexes with a catalytic $\alpha$ subunit (the actual kinase that is activated by T-loop phosphorylation) and two regulatory subunits, called $\beta$ (acts as scaffolding) and $\gamma$ (for nucleotide binding). The regulatory subunits are required for stability, substrate specificity, localization and activity modulation [41,108]. In plants, a hybrid $\beta \gamma$ protein functions as the canonical $\gamma$-subunit and assembles into a hetero-trimeric complex [109]. Composition of SnRK1 heterotrimeric complex and transcriptional regulation of the non-catalytic subunits provide a means for fine-tuning of SnRK1 activity not only to specific developmental stages, autotrophic or heterotrophic tissues, or cellular compartments, but also to environmental conditions and stimuli where SnRK1 can have quite different roles [110-113].

\subsection{SnRK1 regulation under abiotic stress: the upstream regulators}

As we mentioned above, it was described that SnRK1 is active under stress conditions, whereas it is inhibited under favorable conditions ("yin-yang model"). One point of SnRK1 activity control is its phosphorylation by upstream kinases, which could activate or inhibit the kinase (Fig. 2). SnRK1 kinase activity requires phosphorylation of a conserved T-loop threonine in the $\alpha$-subunit $[39,114,115]$. The first SnRK1 upstream kinases that were characterized, which phosphorylate the T- loop at the catalytic subunit, were SnRK1-activating kinase-1 and -2 (SnAK1 and SnAK2), originally identified as geminivirus rep-interacting kinases (GRIK1 and GRIK2) [116,117]. Recently, the activation of SnRK1 by SnAK/GRIK has been shown to act during salt stress tolerance [118]. Moreover, CIPK15 (calcineurin B-like (CBL)-interacting protein kinase) was demonstrated to interact and positively regulate SnRK1A in $\mathrm{O}_{2}$-deficiency in rice, even though, the activation by phosphorylation still remains to be demonstrated [119]. On the other hand, there are upstream kinases that inhibit SnRK1 activity. One example is the suppressor of cell death Adi3, which interacts and specifically phosphorylates SnRK1 $\beta$-subunits [120]. Moreover, SnRK1 activity is negatively regulated by dephosphorylation [121,122]. Two protein phosphatases type 2C (PP2C), ABI1 and PP2CA, were reported to interact and dephosphorylate SnRK1 $\alpha$ catalytic subunit [121]. Moreover, different proteins interact and negatively regulate the activity of SnRK1, such as SnRK1A-interacting negative regulators (SKINs) and Pleiotropic Regulatory Locus1 (PRL1) [123,124] (Fig. 2). Other mechanisms involved in SnRK1 activity control are N-terminal myristoylation (N-MYR) at the $\beta$ subunits, which could affect the membrane binding properties of proteins [125], and lysine acetylation, which requires more research [41].

Remarkably, in plants, under stress conditions, SnRK1 could be negatively regulated [41]. In this regard, SnRK1.1 is repressed by SIZ1dependent (poly-) SUMOylation with the subsequent ubiquitination and proteasome-dependent degradation [126]. Furthermore, Jamsheer et al. [127] proposed an additional layer of control over the SnRK1 activity, where SnRK1 induces the scaffold FLZ6 and FLZ10 (FCS-like zinc finger) proteins. Those proteins repress SnRK1.1 during energy deficit, suggesting an important mechanism to prevent hyperactivation of SnRK1 and thus to modulate the stress response. Noticeably, SnRK1 inhibition and degradation is strictly dependent on its own catalytic activity. Taken together, these mechanisms provide an efficient negative feedback loop that precludes a persistent high SnRK1 activity in stress response [126,127]. Thus, SnRK1 could be negatively fine-tuned regulated during abiotic stress, when an active TOR kinase could have a role despite of energy-limiting conditions ("yin- yang" model).

Sugars and sugar-phosphates are upstream effectors of SnRK1 kinase. It was reported that sugar phosphate, instead of the AMP:ATP ratio, can directly inactivate the plant SnRK1 [41,128]. While repression of SnRK1 activity by sufficient C supply is well established, a number of studies have also demonstrated an induction of SnRK1 activity by Suc $[113,124]$. Stress conditions do not necessarily lead to C depletion. Thus, growth impairment may be limited by Suc accumulation, which could be mediated by SnRK1 signaling. Suc levels appear to be followed by Trehalose 6-Phosphate (Tre6P) levels under abiotic stress conditions [12]. Correlations between Tre6P, Suc and the expression of SnRK1 marker genes, but not with growth rate, have been observed under cold and N deficiency in Arabidopsis [12]. Tre6P acts as a negative regulator of SnRK1 activity in different plant tissues, except for fully mature and senescing leaves [129]. A possible underlying mechanism is that Tre6P directly binds to SnRK1.1 protein and weakens GRIK1-SnRK1.1 association, reducing both the phosphorylation of SnRK1.1 and its activity [130]. In addition, other phosphorylated sugars, such as glucose-1-phosphate (G1P) and glucose-6-phosphate (G6P), negatively regulate SnRK1 activity [12,115,128]. Nevertheless, the molecular mechanisms by which phosphorylated sugars regulate SnRK1 activity still remain unknown. One possibility is that the hexoseto-sucrose ratio alteration, rather than individual sugar levels, could be involved in the response to stress.

Stress conditions trigger the accumulation of ROS, which cause significant damage to cellular structures, but also function as important signaling molecules [103]. DCMU (3-(3,4-dichlorophenyl)-1,1-dimethylurea) treatment induces chloroplast-ROS production and SnRK1 activation [39]. Furthermore, short-term $(2 \mathrm{~h})$ oxidative treatment with methyl viologen (MV), which induces chloroplast- and mitochondriaROS production, induced catabolic pathways in Arabidopsis [131]. These results could be related to SnRK1 activity increase. However, it was shown that high concentration of $\mathrm{H}_{2} \mathrm{O}_{2}(1 \mathrm{mM})$ inhibits SnRK1 kinase activity in vitro [132]. Wurzinger et al. [133] proposed that SnRK1-ROS inhibition could be related to hypoxia-induced SnRK1 signaling at the beginning of the re-oxygenation phase. Disagreements between those results may be due to different experiment designs (performed in vitro or in vivo), type and concentration of ROS, site of ROS generation and duration of exposure to ROS, among other reasons. Moreover, we cannot rule out a retrograde ROS signaling, which could 


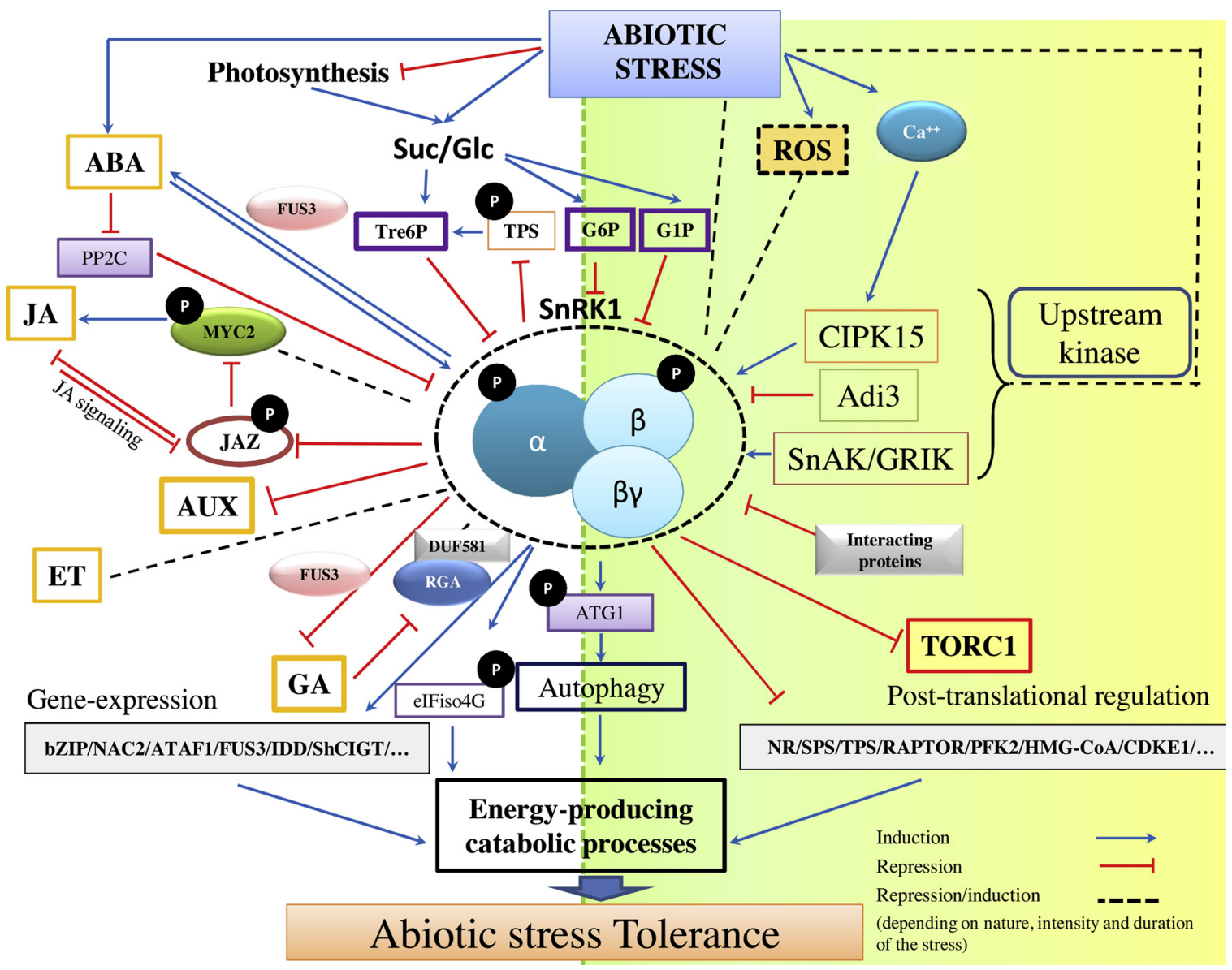

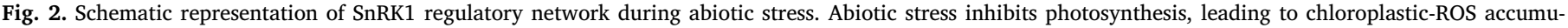

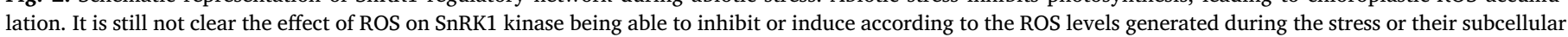

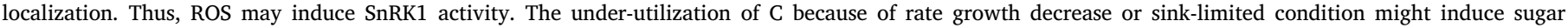

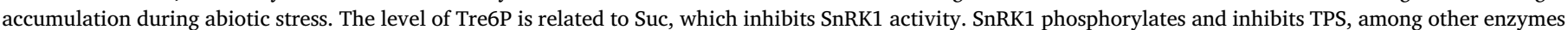

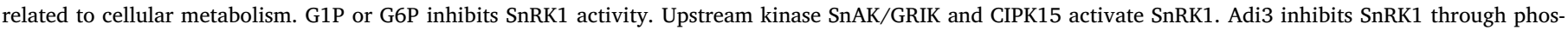
phorylation of the $\beta$ subunit. PP2Cs proteins dephosphorylate and inhibit SnRK1 $\alpha$.

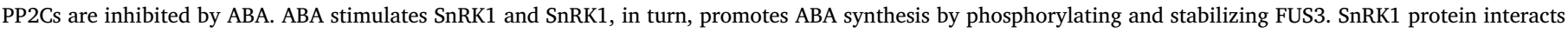

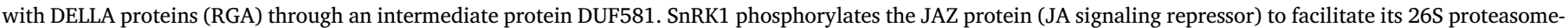

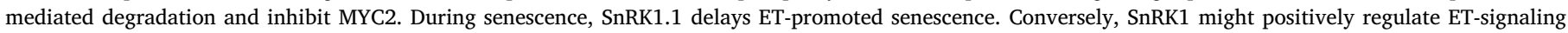

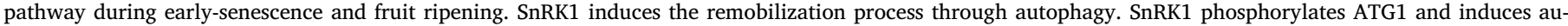

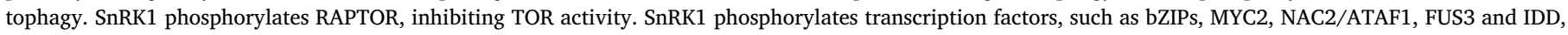

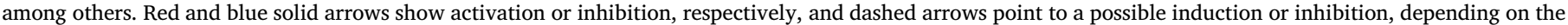
nature, intensity and/or duration of the abiotic stress. See Section 3 and 4 for further details.

contribute to the biological response. The challenges of studying SnRK1-ROS pathways are huge, and include technical limitations that may restrict the comparison between studies [101,132,134].

\subsection{Effect of SnRK1 on downstream targets during abiotic stress}

The activation of SnRK1 initiates massive transcriptional changes, possibly by affecting a number of transcription factors. Recent advances have identified numerous SnRK1.1 targets, such as bZIPs, MYC2, NAC2/ATAF1, FUSCA 3 (FUS3); and ShCIGT [135-141]. For instance, the C/S1 bZIP network appears to mediate SnRK1 downstream signaling during low-energy and osmotic stress. In this regard, SnRK1 changed bZIP63 dimerization preference, thereby affecting target gene expression and ultimately primary metabolism [138]. In addition, SnRK1.1 phosphorylates MYC2, a key regulator of JA signaling, reducing protein stability and transcriptional activity of IDD8, which regulates seedling survival under submergence [137].

SnRK1 also targets crucial regulatory points in metabolic pathways by direct phosphorylation of biosynthetic enzymes, such as glycolysis- related proteins such as 6-phosphofructo-2-kinase/fructose-2,6-biphosphatase (PFK2), glycogen synthase (GYS). Proteins related to lipid metabolism and transport include HMG-CoA reductase, the rate-limiting step in sterol synthesis [142,143] and proteins involved in cell cycle control (cyclin A and D) [144]. Interestingly, the CYCLIN-DEPENDENT KINASE E1 (CDKE1/RAO1) was identified to interact with SnRK1.1 and was proposed to be a hub of retrograde signaling from mitochondria as well as chloroplasts [145-147]. Other SnRK1 targets are Sucrose Phosphate Synthase (SPS), Trehalose Phosphate Synthase (TPS) and Nitrate Reductase (NR), which are negatively regulated by SnRK1 [129,148]. Moreover, quantitative phosphoproteomics in the snrk1.1/1.2 Arabidopsis mutant revealed alteration of phosphorylation levels of several differentially phosphorylated sites in organellar proteins, most prominently the chloroplast ones [149].

Furthermore, it is also important to mention that SnRK1 have other downstream targets during abiotic stress; particularly, some of them are involved in phytohormone pathways and autophagy process. These issues are discussed in sections 3.3 and 3.4, respectively. Finally, the interaction between SnRK1 and TOR is described in section 4. 


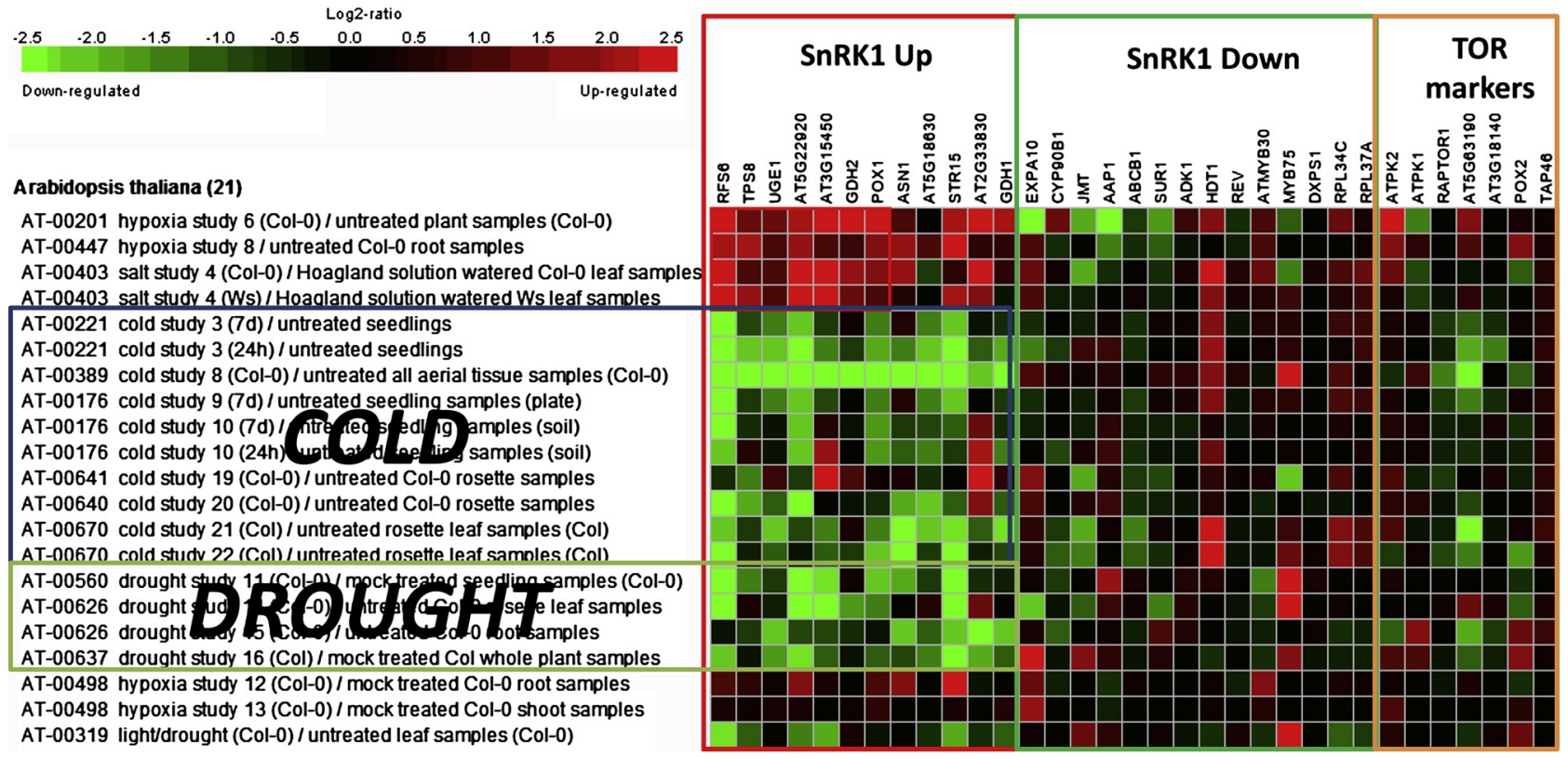

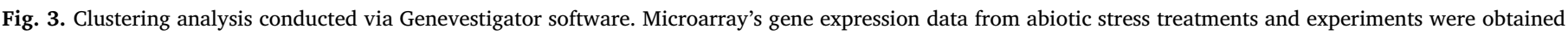

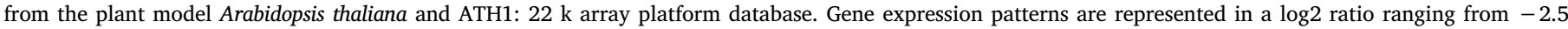

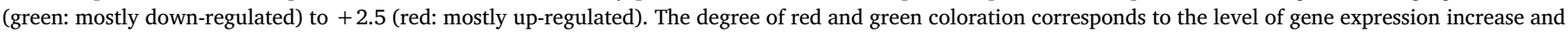

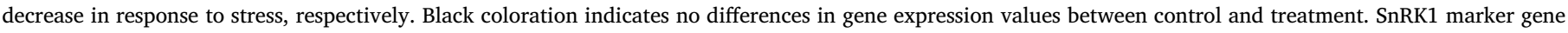

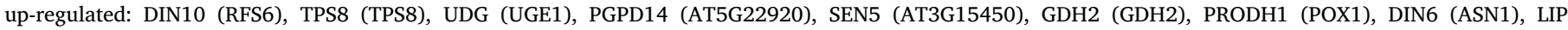

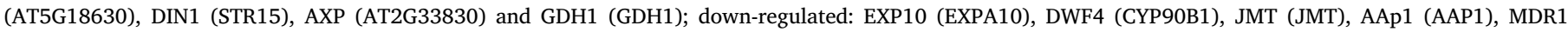

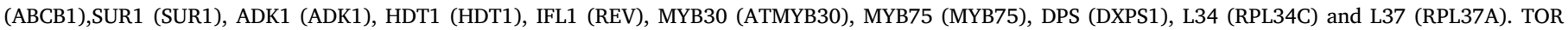
marker genes: S6K2 (ATPK2), S6K1 (ATPK1), RAPTOR1 (RAPTOR1), MRF1 (AT5G3190), LST8-1 (AT3G18140), PRODH2 (POX2) and TAP46 (TAP46).

\subsection{The link between SnRK1 signaling and phytohormone during abiotic} stress response

In a physiological context, SnRK1 kinase exhibits connections with plant hormonal signaling pathways (Fig. 2). Overall, SnRK1 negatively regulates growth-promoting hormones. In this regard, SnRK1.1 could negatively regulate AUX through bZIP11 phosphorylation, which directly promotes the expression of IAA3/SHY2 (a negative regulator of AUX signaling) [150]. Furthermore, another growth promoting hormone that showed a connection with SnRK1 signaling is BR. SnRK1.1, for instance, represses DWF4 protein, which encodes a 22-hydroxylase that catalyzes a rate-limiting step in the BR biosynthetic pathway [39]. Regarding GA hormone, SnRK1 could repress GA biosynthesis through FUS3 [151,152]. GA is perceived by the GA-INSENSITIVE DWARF 1 (GID1) receptors, which in turn mediate degradation of DELLA proteins [153]. Hou et al. [154] showed that more than $28 \%$ of the genes induced by SnRK1.1 were also induced by the DELLA protein RGA. In addition, Niestsche et al. [155] demonstrated the interaction of SnRK1.1 with RGA protein through an intermediate protein DUF581. In this context, the effect of SnRK1-DELLA protein interaction during abiotic stress is still unknown.

The signaling of the stress hormone ABA and SnRK1 is mutually coordinated. SnRK1 acts by phosphorylating and stabilizing FUS3, which promotes ABA synthesis, whereas ABA in turn stimulates SnRK1 [135]. Moreover, ABA inhibits PP2C phosphatase, which can also negatively regulate SnRK1 by dephosphorylation in mature photosynthetic tissues [121]. Liu et al. [156] demonstrated a functional link between SnRK1 and ABA signaling, in which the overexpression of the C2 domain ABA Insensitive Protein1 (CAIP1) caused insensitivity toward ABA. Active SnRK1 rescues this phenotype by direct phosphorylation of CAIP1.

Furthermore, a connection between SnRK1 and the hormones ET and JA was reported. On the one hand, SnRK1 might positively regulate ET-signaling pathway during senescence and fruit ripening, when the catabolism and remobilization are increased. For instance, Yu et al. [141] demonstrated that SnRK1 increased the expression of key genes in ethylene synthesis in tomato (Solanum lycopersicum L.) fruit. On the other hand, SnRK1.1 antagonistically modulates EIN3, and thereby delays ethylene-promoted senescence [157]. In addition, a study in etr1 mutants demonstrated that lack of ET responsiveness induces SnRK1.1 expression, which inhibits the promotion of ET-inducible hypocotyl growth under light [158]. Moreover, a link between SnRK1 and JA signaling exists, since it was reported that SnRK1.1 phosphorylates the JAZ18 protein, a JA signaling repressor, to facilitate its $26 \mathrm{~S}$ proteasome-mediated degradation in apple [159]. However, SnRK1.1 overexpression resulted in decreased MYC2 (a key regulator of JA signaling) protein levels, which induce salt water tolerance [137].

\subsection{SnRK1 activity is involved in abiotic stress tolerance}

SnRK1 can be activated by multiple abiotic stress conditions (Fig. 2) $[41,108]$. For instance, it is well documented that SnRK1 activation is triggered by hypoxia, leading to an increase in catabolism and production of alternative energy sources [137,160,161]. Recently, Soltani et al. [162] identified genomic regions associated with flooding tolerance close to SnRK1 in bean plants. Under submergence, SnRK1.1 phosphorylates the translation initiation factor, eIFiso4G, to regulate the stress response [161]. In this regard, SnRK1 induces marker genes for the flooding stress response, such as alcohol deshydrogenase1 (ADH1) and pyruvate decarboxylase1 (PDC1) [161]. Additionally, SnRK1.1-overexpressing lines can induce tolerance to hypoxia by increasing autophagy [163]. SnRK1.1 regulates autophagy by affecting the phosphorylation of ATG1 [163]. Moreover, SnRK1 redox regulation might also induce autophagy during abiotic stresses; however, this issue is still unclear $[164,165]$.

Furthermore, transgenic Arabidopsis lines overexpressing SnRK1.1 showed drought tolerance [163]. One possible mechanism by which SnRK1 could affect stress response pathways is through ABA signaling 
(see section 3.3). However, genes described as SnRK1.1 up-regulated were found to be down-regulated under water deficit condition (Fig. 3). Thus, these seemingly contradictory results suggest a complex regulation of ABA-SnRK1 axis.

Another important aspect related to abiotic stress tolerance induced by SnRK1 is the fine-tuning regulation of SnRK1 heterotrimeric complex. In this context, transgenic potato plants altered in the expression of the subunit $\beta$-SnRK1 showed a phenotype of hypersensitivity to salt [166]. In addition, during germination of Medicago truncatula seeds, for example, $\beta$ and $\gamma$ subunit genes are differentially regulated in response to osmotic stress and desiccation tolerance [167].

\section{Do SnRK1 and TOR signaling pathways act according to the "yin-yang" model during abiotic stress conditions?}

It is widely accepted that TOR and SnRK1 interact closely and work in balance with metabolic process $[33,40,41]$. In plants, SnRK1.1 can interact and phosphorylate RAPTOR1B in vivo and in vitro, inhibiting TOR activity [149,155]. Although this interaction may require the scaffolding action of the plant-specific DUF581-19/MARD1 protein, as shown in yeast two-hybrid assays [155,168]. Recently, other proteins belonging to FLZ family of proteins, which participate in TOR-SnRK1 dynamics interaction, were also described [127]. Those proteins act as an adaptor of SnRK1 and regulate the stability of SnRK1 kinase subunit [127,155]. Global phosphoproteomic analyses of plants with altered SnRK1 activity have also revealed altered phosphorylation levels of classical TOR targets such as RPS6 and translation initiation factors $[149,160]$. Thus, the behavior of TOR and SnRK1 follows the "yinyang" model; however, under certain physiological circumstances, that antagonism might be ambiguous and the kinases might act in a different way. In line with this, we have described several facts: i- some stresses lead to the accumulation of sucrose, which is an inductor of TOR and an indirect repressor of SnRK1; ii- TOR and SnRK1 activities are necessary for ABA synthesis; iii- TOR is involved in glutathione synthesis; iv- TOR and SnRK1 overexpressor lines induce stress-responsive genes; v- TOR activity, besides SnRK1, may be required for the stress response, as suggested by some reports and unpublished results conducted in our laboratory; vi- TOR and SnRK1 roles during senescence process induced by abiotic stresses yielded conflicting results. For instance, ethano1-induced silencing of AtTOR expression triggered an early yellowing [90] and SnRK1 overexpression delayed senescence process [45].

Moreover, it is remarkable that the target genes of TOR and SnRK1 kinases only partially, and not always antagonistically, overlay under energy deficiency [36]. Baena Gonzalez et al. [39] analyzed global gene expression regulation by SnRK1.1 and selected SnRK1.1 marker genes, which are activated/repressed at the mesophyll cellular level. In this context, in order to analyze TOR and SnRK1 signaling under abiotic stress, we selected marker genes which are up- and down-regulated in relation to TOR and SnRK1 activities. These genes were analyzed by biclustering in genevestigator software, taking into account experiments involving abiotic stress treatments (Fig. 3). In general, we observed that genes described as up-regulated by SnRK1.1 were found to be down-regulated by cold and drought stress. In line with this, Nunes et al. [12] performed cold stress experiments $\left(10^{\circ} \mathrm{C}\right)$ and observed an early decrease of SnRK1 activity with respect to control (up to $48 \mathrm{~h}$ ). In this regard, a TOR-RNAi line was found to be cold sensitive [94]. Moreover, a TOR overexpressor line in rice was described as more tolerant to drought condition than the control treatment [46]. Altogether, these results suggest that an active TOR might induce cold and drought tolerance, and one possibility could be through the biosynthesis of protective metabolites. Dobrenel et al. [169] suggested that TOR activity may be required for the adaptation to stress by the induction of myo-inositol and raffinose family oligosaccharide (RFO) synthesis. This is consistent with the fact that RFO may contribute to overall cellular ROS homeostasis by specific ROS scavenging processes [170,171]. Furthermore, SnRK1 activity might result in an increased level of RFO through bZIP activity in Arabidopsis, which is consistent with RFO and SnRK1 increase under stress condition [138,169,172,173]. Moreover, proline is another protective metabolite that is involved in stress responses. Accordingly, one of the marker genes normally induced by SnRK1 is proDH1 (Proline Dehydrogenase1, POX1), which codes for a key enzyme in the catabolism of proline [90]. Summarizing, the effect of TOR and SnRK1 signaling on the accumulation of stress-regulated metabolites is not clear and needs to be explored.

On the other hand, hypoxia and salt stress induce the expression of the up-regulated SnRK1 marker genes. Nevertheless, marker genes that are normally down-regulated by SnRK1 signaling pathway did not show a common expression pattern during abiotic stress (Fig. 3). Therefore, the intricate networks of gene transcription regulation in response to stressors are still not fully understood, as demonstrated by these results. It is tempting to speculate that regulators, other than SnRKs, may modulate TOR activity under stress conditions, a possibility that needs to be explored.

\section{Conclusion and future perspectives}

Over the years, conventional breeding programs have developed crops with fast growth and high yields. However, these traits involve trade-offs with other traits, such as stress-tolerance [174]. A tight regulation of the energy intake/expenditure balance is a major challenge for plant breeders and, therefore, identifying and characterizing the roles of TOR and SnRK1 kinases under abiotic stresses is crucial.

TOR and SnRK1 enzymatic activities respond in an opposite way, according to the "yin-yang" model. Both enzymes are tightly and dynamically regulated, at multiple levels, to maintain cellular homeostasis and allow plant survival under stress. Thus, in response to unfavorable conditions, TOR and SnRK1 could act differently than expected in the extreme situations of the "yin-yang" model. For example, it is widely accepted that SnRK1 activity increases under stress condition. However, emerging evidences suggest that active TOR is required for a successful stress response. Thus, it is tempting to speculate that there is a wide gradient of responses (palette of grays) between the extremes of feast-famine situations (white and black of the "yin-yang" drawing), where TOR is not necessarily inhibited, whereas SnRK1 is activated under stress. Moreover, we cannot rule out that the kinase activities would not be opposite due to different subcellular compartments at any given time of stress. Particularly, subcellular localization of the TOR complex under stress conditions was scarcely investigated. Furthermore, it would be interesting to investigate the possible existence of Raptor bodies in plants or the relationship between TOR and stress granules. Another important point is that TOR and SnRK1 signaling pathway regulation depends on the nature of the stressor, the length and intensity of the stress, the plant cellular type (heterotrophic or autotrophic) and the physiological context.

It has been frequently described that the response of plants to stress is highly complex and includes a plethora of possibilities [175]. In this regard, the design of the experiments to evaluate the effect of abiotic stresses is extremely important and special care must be taken when published results are compared. In accordance with this, future research on plant response to abiotic stresses needs to unify criteria and facilitate comparisons (e.g., using severity indices). Besides, the research with Arabidopsis lines in which TOR or SnRK1 signaling are up- or downregulated is a useful tool to dissect the functions of the kinases, but the extremely artificial metabolic imbalance that it causes has to be taken in account. One clear example is the still unknown specific role of these kinases in leaf senescence, of which there are contrasting results in conditional TOR mutants and pharmacologically inhibited TOR signaling [110,176]. Moreover, Table 1 shows the scarce information about TOR/SnRK1 signaling in crop plants. Future research should be addressed about this issue in order to obtain crop plants tolerant to abiotic stress, but without penalties in growth or productivity.

Finally, the knowledge of TOR/SnRK1 interactome as well as redox 
regulation under abiotic stresses would provide valuable information to dissect the signaling pathway. It is clear that more research is needed to expand knowledge about the exact mechanisms of action of TOR and SnRK1 and their interactions with other key networks under abiotic stresses.

Author contributions:

MR and GMN designed the manuscript and figures. RP conducted the genevestigator analyses and figures. SA conducted the table. CP contributed with figures and caption. MR and GMN analyzed the data, discuss and drafted the manuscript. MR, RP, SA, CP and GMN co-wrote the manuscript.

\section{Declaration of Competing Interest}

The authors declare that they have no conflict of interest

\section{Acknowledgements}

We apologize to the many researchers whose work was not cited due to space constraints. We thank Dr. E. Taleisnik and Dr. J. Tognetti for a careful review of the manuscript. This work was supported by INTA, CONICET and Agencia Nacional de Promoción Científica y Tecnológica (PICT2016-0173).

\section{References}

[1] H.C.J. Godfray, J.R. Beddington, I.R. Crute, L. Haddad, D. Lawrence, J.F. Muir, J. Pretty, S. Robinson, S.M. Thomas, C. Toulmin, Food security: the challenge of feeding 9 billion people, Science 327 (2010) 812-818, https://doi.org/10.1126/ science. 1185383.

[2] R.N. Strange, P.R. Scott, Plant disease: a threat to global food security, Annu. Rev. Phytopathol. 43 (2005) 83-116, https://doi.org/10.1146/annurev.phyto.43. 113004.133839.

[3] P. Ronald, Plant Genetics, Sustainable Agriculture and Global Food Security, Genetics. 188 (2011) 11-20, https://doi.org/10.1534/genetics.111.128553.

[4] E.R. Rhodes, A. Jalloh, A. Diouf, Review of Research and Policies for Climate Change Adaptation in the Agriculture Sector in West Africa, (2014), p. 52.

[5] N.G. Halford, T.Y. Curtis, Z. Chen, J. Huang, Effects of abiotic stress and crop management on cereal grain composition: implications for food quality and safety, J. Exp. Bot. 66 (2015) 1145-1156, https://doi.org/10.1093/jxb/eru473.

[6] M. Thalmann, D. Santelia, Starch as a determinant of plant fitness under abiotic stress, New Phytol. 214 (2017) 943-951, https://doi.org/10.1111/nph.14491.

[7] J. Krasensky, C. Jonak, Drought, salt, and temperature stress-induced metabolic rearrangements and regulatory networks, J. Exp. Bot. 63 (2012) 1593-1608, https://doi.org/10.1093/jxb/err460.

[8] S. Dong, J. Zhang, D.M. Beckles, A pivotal role for starch in the reconfiguration of $14 \mathrm{C}$-partitioning and allocation in Arabidopsis thaliana under short-term abiotic stress, Sci. Rep. 8 (2018) 9314, https://doi.org/10.1038/s41598-018-27610-y.

[9] S.P. Slocombe, F. Beaudoin, P.G. Donaghy, D.G. Hardie, J.R. Dickinson, N.G. Halford, SNF1-related protein kinase (SnRK1) phosphorylates class I heat shock protein, Plant Physiol. Biochem. 42 (2004) 111-116, https://doi.org/10. 1016/j.plaphy.2003.11.009.

[10] J.A.S. Barros, J.H.F. Cavalcanti, D.B. Medeiros, A. Nunes-Nesi, T. Avin-Wittenberg, A.R. Fernie, W.L. Araújo, Autophagy Deficiency Compromises Alternative Pathways of Respiration following Energy Deprivation in Arabidopsis thaliana, Plant Physiol. 175 (2017) 62-76, https://doi.org/10.1104/pp.16.01576.

[11] H.C. Janse van Rensburg, W. Van den Ende, S. Signorelli, Autophagy in plants: both a puppet and a puppet master of sugars, Front. Plant Sci. 10 (2019), https:// doi.org/10.3389/fpls.2019.00014.

[12] C. Nunes, L.E. O'Hara, L.F. Primavesi, T.L. Delatte, H. Schluepmann, G.W. Somsen, A.B. Silva, P.S. Fevereiro, A. Wingler, M.J. Paul, The Trehalose 6-Phosphate/ SnRK1 Signaling Pathway Primes Growth Recovery following Relief of Sink Limitation, Plant Physiol. 162 (2013) 1720-1732, https://doi.org/10.1104/pp. 113.220657.

[13] M.L. Nuccio, J. Wu, R. Mowers, H.-P. Zhou, M. Meghji, L.F. Primavesi, M.J. Paul, X. Chen, Y. Gao, E. Haque, S.S. Basu, L.M. Lagrimini, Expression of trehalose-6phosphate phosphatase in maize ears improves yield in well-watered and drought conditions, Nat. Biotechnol. 33 (2015) 862-869, https://doi.org/10.1038/nbt. 3277.

[14] C. Henry, S.W. Bledsoe, C.A. Griffiths, A. Kollman, M.J. Paul, S. Sakr, L.M. Lagrimini, Differential role for trehalose metabolism in Salt-Stressed maize, Plant Physiol. 169 (2015) 1072-1089, https://doi.org/10.1104/pp.15.00729.

[15] E. Martinez-Barajas, T. Delatte, H. Schluepmann, G.J. de Jong, G.W. Somsen, C. Nunes, L.F. Primavesi, P. Coello, R.A.C. Mitchell, M.J. Paul, Wheat grain development is characterized by remarkable trehalose 6-Phosphate accumulation pregrain filling: tissue distribution and relationship to SNF1-Related protein Kinase1 activity, Plant Physiol. 156 (2011) 373-381, https://doi.org/10.1104/pp. 111.174524.
[16] V. Oury, C.F. Caldeira, D. Prodhomme, J.-P. Pichon, Y. Gibon, F. Tardieu, O. Turc, Is Change in Ovary Carbon Status a Cause or a Consequence of Maize Ovary Abortion in Water Deficit during Flowering? Plant Physiol. 171 (2016) 997-1008, https://doi.org/10.1104/pp.15.01130.

[17] A. Wormit, O. Trentmann, I. Feifer, C. Lohr, J. Tjaden, S. Meyer, U. Schmidt, E. Martinoia, H.E. Neuhaus, Molecular identification and physiological characterization of a novel monosaccharide transporter from Arabidopsis Involved in Vacuolar Sugar Transport, Plant Cell 18 (2006) 3476-3490, https://doi.org/10. 1105/tpc.106.047290.

[18] I.I. Hoermiller, T. Naegele, H. Augustin, S. Stutz, W. Weckwerth, A.G. Heyer, Subcellular reprogramming of metabolism during cold acclimation in Arabidopsis thaliana, Plant, Cell \& Environment. 40 (2017) 602-610, https://doi.org/10. $1111 /$ pce. 12836.

[19] T. Nägele, A.G. Heyer, Approximating subcellular organisation of carbohydrate metabolism during cold acclimation in different natural accessions of Arabidopsis thaliana, New Phytol. 198 (2013) 777-787, https://doi.org/10.1111/nph.12201.

[20] L. Fürtauer, W. Weckwerth, T. Nägele, A benchtop fractionation procedure for subcellular analysis of the plant metabolome, Front. Plant Sci. 7 (2016), https:// doi.org/10.3389/fpls.2016.01912.

[21] F. Rolland, B. Moore, J. Sheen, Sugar sensing and signaling in plants, Plant Cell 14 (2002) S185-S205, https://doi.org/10.1105/tpc.010455.

[22] F. Rolland, E. Baena-Gonzalez, J. Sheen, Sugar Sensing and Signaling in Plants: Conserved and Novel Mechanisms, Annu. Rev. Plant Biol. 57 (2006) 675-709, https://doi.org/10.1146/annurev.arplant.57.032905.105441.

[23] A.L. Eveland, D.P. Jackson, Sugars, signalling, and plant development, J. Exp. Bot. 63 (2012) 3367-3377, https://doi.org/10.1093/jxb/err379.

[24] Y.-L. Ruan, Signaling role of sucrose metabolism in development, Mol. Plant 5 (2012) 763-765, https://doi.org/10.1093/mp/sss046.

[25] M. Ramon, F. Rolland, J. Sheen, Sugar sensing and signaling, Arabidopsis Book 6 (2008), https://doi.org/10.1199/tab.0117.

[26] J.A. Tognetti, H.G. Pontis, G.M.A. Martínez-Noël, Sucrose signaling in plants, Plant Signal. Behav. 8 (2013), https://doi.org/10.4161/psb.23316.

[27] J.C. Grigston, D. Osuna, W.-R. Scheible, C. Liu, M. Stitt, A.M. Jones, d -Glucose sensing by a plasma membrane regulator of $\mathrm{G}$ signaling protein,At RGS1, FEBS Lett. 582 (2008) 3577-3584, https://doi.org/10.1016/j.febslet.2008.08.038.

[28] M.J. Paul, L.F. Primavesi, D. Jhurreea, Y. Zhang, Trehalose metabolism and signaling, Annu. Rev. Plant Biol. 59 (2008) 417-441, https://doi.org/10.1146/ annurev.arplant.59.032607.092945.

[29] J. Ponnu, V. Wahl, M. Schmid, Trehalose-6-Phosphate: connecting plant metabolism and development, Front. Plant Sci. 2 (2011), https://doi.org/10.3389/fpls. 2011.00070.

[30] E.A. Ainsworth, D.R. Bush, Carbohydrate export from the leaf: a highly regulated process and target to enhance photosynthesis and productivity, Plant Physiol. 155 (2011) 64-69, https://doi.org/10.1104/pp.110.167684.

[31] S. Smeekens, H.A. Hellmann, Sugar sensing and signaling in plants, Front. Plant Sci. 5 (2014), https://doi.org/10.3389/fpls.2014.00113.

[32] A. Wingler, Transitioning to the next phase: the role of sugar signaling throughout the plant life cycle, Plant Physiol. 176 (2018) 1075-1084, https://doi.org/10. 1104/pp.17.01229.

[33] E. Baena-González, J. Hanson, Shaping plant development through the SnRK1-TOR metabolic regulators, Curr. Opin. Plant Biol. 35 (2017) 152-157, https://doi.org/10.1016/j.pbi.2016.12.004.

[34] L. Shi, Y. Wu, J. Sheen, TOR signaling in plants: conservation and innovation, Development. 145 (2018), https://doi.org/10.1242/dev.160887 dev160887.

[35] B. Menand, T. Desnos, L. Nussaume, F. Berger, D. Bouchez, C. Meyer, C. Robaglia, Expression and disruption of the Arabidopsis TOR (target of rapamycin) gene, PNAS. 99 (2002) 6422-6427, https://doi.org/10.1073/pnas.092141899.

[36] Y. Wu, L. Shi, L. Li, L. Fu, Y. Liu, Y. Xiong, J. Sheen, Integration of nutrient, energy, light and hormone signalling via TOR in plants, J. Exp. Bot. (2019) 2227-2238, https://doi.org/10.1093/jxb/erz028.

[37] T. Dobrenel, C. Marchive, R. Sormani, M. Moreau, M. Mozzo, M.-H. Montané, B. Menand, C. Robaglia, C. Meyer, Regulation of plant growth and metabolism by the TOR kinase, Biochem. Soc. Trans. 39 (2011) 477-481, https://doi.org/10. 1042/BST0390477.

[38] L.A. Ryabova, C. Robaglia, C. Meyer, Target of Rapamycin kinase: central regulatory hub for plant growth and metabolism, J. Exp. Bot. 70 (2019) 2211-2216, https://doi.org/10.1093/jxb/erz108.

[39] E. Baena-González, F. Rolland, J.M. Thevelein, J. Sheen, A central integrator of transcription networks in plant stress and energy signalling, Nature. 448 (2007) 938-942, https://doi.org/10.1038/nature06069.

[40] C. Robaglia, M. Thomas, C. Meyer, Sensing nutrient and energy status by SnRK1 and TOR kinases, Curr. Opin. Plant Biol. 15 (2012) 301-307, https://doi.org/10. 1016/j.pbi.2012.01.012.

[41] T. Broeckx, S. Hulsmans, F. Rolland, The plant energy sensor: evolutionary conservation and divergence of SnRK1 structure, regulation, and function, J. Exp. Bot 67 (2016) 6215-6252, https://doi.org/10.1093/jxb/erw416.

[42] T. Dobrenel, C. Caldana, J. Hanson, C. Robaglia, M. Vincentz, B. Veit, C. Meyer, TOR signaling and nutrient sensing, Annu. Rev. Plant Biol. 67 (2016) 261-285, https://doi.org/10.1146/annurev-arplant-043014-114648.

[43] F. Tomé, T. Nägele, M. Adamo, A. Garg, C. Marco-llorca, E. Nukarinen, L. Pedrotti, A. Peviani, A. Simeunovic, A. Tatkiewicz, M. Tomar, M. Gamm, The low energy signaling network, Front. Plant Sci. 5 (2014), https://doi.org/10.3389/fpls.2014. 00353.

[44] Y. Pu, X. Luo, D.C. Bassham, TOR-dependent and -Independent pathways regulate autophagy in Arabidopsis thaliana, Front. Plant Sci. 8 (2017), https://doi.org/10. 3389/fpls.2017.01204. 
[45] Y.-H. Cho, J.-W. Hong, E.-C. Kim, S.-D. Yoo, Regulatory functions of SnRK1 in stress-responsive gene expression and in plant growth and development, Plant Physiol. 158 (2012) 1955-1964, https://doi.org/10.1104/pp.111.189829.

[46] A. Bakshi, M. Moin, M.U. Kumar, A.B.M. Reddy, M. Ren, R. Datla, E.A. Siddiq, P.B. Kirti, Ectopic expression of Arabidopsis target of Rapamycin (AtTOR) improves water-use efficiency and yield potential in rice, Sci. Rep. 7 (2017) 42835, https:// doi.org/10.1038/srep42835.

[47] M. Schepetilnikov, L.A. Ryabova, Recent discoveries on the role of TOR (Target of rapamycin) signaling in translation in plants, Plant Physiol. 176 (2018) 1095-1105, https://doi.org/10.1104/pp.17.01243.

[48] C. Caldana, M.C.M. Martins, U. Mubeen, R. Urrea-Castellanos, The magic 'hammer' of TOR: the multiple faces of a single pathway in the metabolic regulation of plant growth and development, J. Exp. Bot. 70 (2019) 2217-2225, https://doi.org/10.1093/jxb/ery459.

[49] Y. Xiong, M. McCormack, L. Li, Q. Hall, C. Xiang, J. Sheen, Glucose-TOR signalling reprograms the transcriptome and activates meristems, Nature. 496 (2013) 181-186, https://doi.org/10.1038/nature12030.

[50] M.-H. Montané, B. Menand, ATP-competitive mTOR kinase inhibitors delay plant growth by triggering early differentiation of meristematic cells but no developmental patterning change, J. Exp. Bot. 64 (2013) 4361-4374, https://doi.org/10. 1093/jxb/ert242.

[51] Y. Xiong, J. Sheen, C Glucose-Target of rapamycin (TOR) protein signaling in plants, J. Biol. Chem. 287 (2012) 2836-2842, https://doi.org/10.1074/jbc.M111. 300749 .

[52] M. Ren, S. Qiu, P. Venglat, D. Xiang, L. Feng, G. Selvaraj, R. Datla, Target of rapamycin regulates development and ribosomal RNA expression through kinase domain in Arabidopsis, Plant Physiol. 155 (2011) 1367-1382, https://doi.org/10. 1104/pp.110.169045.

[53] M.M. Mahfouz, S. Kim, A.J. Delauney, D.P.S. Verma, Arabidopsis TARGET OF RAPAMYCIN interacts with RAPTOR, which regulates the activity of S6 kinase in response to osmotic stress signals, Plant Cell 18 (2006) 477-490, https://doi.org/ 10.1105/tpc.105.035931.

[54] M. Moreau, M. Azzopardi, G. Clément, T. Dobrenel, C. Marchive, C. Renne, M.L. Martin-Magniette, L. Taconnat, J.-P. Renou, C. Robaglia, C. Meyer, Mutations in the Arabidopsis homolog of LST8/GßL, a partner of the target of rapamycin kinase, impair plant growth, flowering, and metabolic adaptation to long days, Plant Cell 24 (2012) 463-481, https://doi.org/10.1105/tpc.111.091306.

[55] C.H.S. Aylett, E. Sauer, S. Imseng, D. Boehringer, M.N. Hall, N. Ban, T. Maier, Architecture of human mTOR complex 1, Science. 351 (2016) 48-52, https://doi. org/10.1126/science.aaa3870.

[56] A. González, M.N. Hall, Nutrient sensing and TOR signaling in yeast and mammals, EMBO J. 36 (2017) 397-408, https://doi.org/10.15252/embj.201696010.

[57] R.A. Saxton, D.M. Sabatini, mTOR signaling in growth, metabolism, and disease, Cell. 168 (2017) 960-976, https://doi.org/10.1016/j.cell.2017.02.004.

[58] Y. Xiong, J. Sheen, Novel links in the plant TOR kinase signaling network, Curr. Opin. Plant Biol. 28 (2015) 83-91, https://doi.org/10.1016/j.pbi.2015.09.006.

[59] D. Rexin, C. Meyer, C. Robaglia, B. Veit, TOR signalling in plants, Biochem. J. 470 (2015) 1-14, https://doi.org/10.1042/BJ20150505.

[60] H. Tatebe, K. Shiozaki, Evolutionary conservation of the components in the TOR signaling pathways, Biomolecules. 7 (2017), https://doi.org/10.3390/ biom7040077.

[61] Y. Dong, M. Silbermann, A. Speiser, I. Forieri, E. Linster, G. Poschet, A.A. Samami, M. Wanatabe, C. Sticht, A.A. Teleman, J.-M. Deragon, K. Saito, R. Hell, M. Wirtz, Sulfur availability regulates plant growth via glucose-TOR signaling, Nat. Commun. 8 (2017) 1174, https://doi.org/10.1038/s41467-017-01224-w.

[62] M. Schepetilnikov, J. Makarian, O. Srour, A. Geldreich, Z. Yang, J. Chicher, P. Hammann, L.A. Ryabova, GTPase ROP2 binds and promotes activation of target of rapamycin, TOR, in response to auxin, EMBO J. 36 (2017) 886-903, https:// doi.org/10.15252/embj.201694816.

[63] A. Pfeiffer, D. Janocha, Y. Dong, A. Medzihradszky, S. Schöne, G. Daum, T. Suzaki, J. Forner, T. Langenecker, E. Rempel, M. Schmid, M. Wirtz, R. Hell, J.U. Lohmann, Integration of light and metabolic signals for stem cell activation at the shoot apical meristem, ELife. 5 (2016), https://doi.org/10.7554/eLife.17023.

[64] W. Cai, X. Li, Y. Liu, Y. Wang, Y. Zhou, T. Xu, Y. Xiong, COP1 integrates light signals to ROP2 for cell cycle activation, Plant Signal. Behav. 12 (2017) e1363946, https://doi.org/10.1080/15592324.2017.1363946.

[65] G.-H. Chen, M.-J. Liu, Y. Xiong, J. Sheen, S.-H. Wu, TOR and RPS6 transmit light signals to enhance protein translation in deetiolating Arabidopsis seedlings, Proc. Natl. Acad. Sci. U. S. A. 115 (2018) 12823-12828, https://doi.org/10.1073/pnas. 1809526115.

[66] R. Enganti, S.K. Cho, J.D. Toperzer, R.A. Urquidi-Camacho, O.S. Cakir, A.P. Ray, P.E. Abraham, R.L. Hettich, A.G. von Arnim, Phosphorylation of ribosomal protein RPS6 integrates light signals and circadian clock signals, Front. Plant Sci. 8 (2018), https://doi.org/10.3389/fpls.2017.02210.

[67] B. Li, Y. Wang, Y. Zhang, W. Tian, K. Chong, J.-C. Jang, L. Wang, PRR5, 7 and 9 positively modulate TOR signaling-mediated root cell proliferation by repressing TANDEM ZINC FINGER 1 in Arabidopsis, Nucleic Acids Res. (2019), https://doi. org/10.1093/nar/gkz191.

[68] M. Schepetilnikov, M. Dimitrova, E. Mancera-Martínez, A. Geldreich, M. Keller, L.A. Ryabova, TOR and S6K1 promote translation reinitiation of uORF-containing mRNAs via phosphorylation of eIF3h, EMBO J. 32 (2013) 1087-1102, https://doi. org/10.1038/emboj.2013.61.

[69] D.-H. Lee, S.J. Park, C.S. Ahn, H.-S. Pai, MRF family genes are involved in translation control, especially under energy-deficient conditions, and their expression and functions are modulated by the TOR signaling pathway, Plant Cell 29 (2017) 2895-2920, https://doi.org/10.1105/tpc.17.00563.
[70] C.S. Ahn, J.-A. Han, H.-S. Lee, S. Lee, H.-S. Pai, The PP2A regulatory subunit Tap46, a component of the TOR signaling pathway, modulates growth and metabolism in plants, Plant Cell 23 (2011) 185-209, https://doi.org/10.1105/tpc 110.074005

[71] C.S. Ahn, H.-K. Ahn, H.-S. Pai, Overexpression of the PP2A regulatory subunit Tap46 leads to enhanced plant growth through stimulation of the TOR signalling pathway, J. Exp. Bot. 66 (2015) 827-840, https://doi.org/10.1093/jxb/eru438.

[72] C.S. Ahn, D.-H. Lee, H.-S. Pai, Characterization of Maf1 in Arabidopsis: function under stress conditions and regulation by the TOR signaling pathway, Planta. 249 (2019) 527-542, https://doi.org/10.1007/s00425-018-3024-5.

[73] L. Li, Y. Song, K. Wang, P. Dong, X. Zhang, F. Li, Z. Li, M. Ren, TOR-inhibitor insensitive-1 (TRIN1) regulates cotyledons greening in Arabidopsis, Front. Plant Sci. 6 (2015) 861, https://doi.org/10.3389/fpls.2015.00861.

[74] A. Barrada, M. Djendli, T. Desnos, R. Mercier, C. Robaglia, M.-H. Montané, B. Menand, A TOR-YAK1 signaling axis controls cell cycle, meristem activity and plant growth in Arabidopsis, Development. 146 (2019), https://doi.org/10.1242/ dev.171298 dev171298.

[75] C. Forzani, G.T. Duarte, J. Van Leene, G. Clément, S. Huguet, C. Paysant-Le-Roux, R. Mercier, G. De Jaeger, A.-S. Leprince, C. Meyer, Mutations of the AtYAK1 kinase suppress TOR deficiency in Arabidopsis, Cell Rep. 27 (2019) 3696-3708, https:// doi.org/10.1016/j.celrep.2019.05.074 e5.

[76] J. Van Leene, C. Han, A. Gadeyne, D. Eeckhout, C. Matthijs, B. Cannoot, N. De Winne, G. Persiau, E. Van De Slijke, B. Van de Cotte, E. Stes, M. Van Bel, V. Storme, F. Impens, K. Gevaert, K. Vandepoele, I. De Smet, G. De Jaeger, Capturing the phosphorylation and protein interaction landscape of the plant TOR kinase, Nat. Plants 5 (2019) 316-327, https://doi.org/10.1038/s41477-0190378-z.

[77] M. Jamsheer K, S. Jindal, A. Laxmi, Evolution of TOR-SnRK dynamics in green plants and its integration with phytohormone signaling networks, J. Exp. Bot. (2019), https://doi.org/10.1093/jxb/erz107.

[78] P. Dong, F. Xiong, Y. Que, K. Wang, L. Yu, Z. Li, R. Maozhi, Expression profiling and functional analysis reveals that TOR is a key player in regulating photosynthesis and phytohormone signaling pathways in Arabidopsis, Front. Plant Sci. 6 (2015) 677, https://doi.org/10.3389/fpls.2015.00677.

[79] K. Deng, L. Yu, X. Zheng, K. Zhang, W. Wang, P. Dong, J. Zhang, M. Ren, Target of rapamycin is a key player for auxin signaling transduction in Arabidopsis, Front Plant Sci. 7 (2016), https://doi.org/10.3389/fpls.2016.00291.

[80] K. Deng, P. Dong, W. Wang, L. Feng, F. Xiong, K. Wang, S. Zhang, S. Feng, B. Wang, J. Zhang, M. Ren, The TOR pathway is involved in adventitious root formation in Arabidopsis and potato, Front. Plant Sci. 8 (2017), https://doi.org/ 10.3389/fpls.2017.00784.

[81] Z. Zhang, J.-Y. Zhu, J. Roh, C. Marchive, S.-K. Kim, C. Meyer, Y. Sun, W. Wang, Z.Y. Wang, TOR signaling promotes accumulation of BZR1 to balance growth with carbon availability in Arabidopsis, Curr. Biol. 26 (2016) 1854-1860, https://doi. org/10.1016/j.cub.2016.05.005.

[82] F. Xiong, R. Zhang, Z. Meng, K. Deng, Y. Que, F. Zhuo, L. Feng, S. Guo, R. Datla, M. Ren, Brassinosteriod Insensitive 2 (BIN2) acts as a downstream effector of the Target of Rapamycin (TOR) signaling pathway to regulate photoautotrophic growth in Arabidopsis, New Phytol. 213 (2017) 233-249, https://doi.org/10 1111/nph.14118.

[83] I. Sharma, N. Kaur, P.K. Pati, Brassinosteroids: a promising option in deciphering remedial strategies for abiotic stress tolerance in rice, Front. Plant Sci. 8 (2017), https://doi.org/10.3389/fpls.2017.02151.

[84] T. Nolan, J. Chen, Y. Yin, Cross-talk of Brassinosteroid signaling in controlling growth and stress responses, Biochem. J. 474 (2017) 2641-2661, https://doi.org/ 10.1042/BCJ20160633.

[85] Y. Song, G. Zhao, X. Zhang, L. Li, F. Xiong, F. Zhuo, C. Zhang, Z. Yang, R. Datla M. Ren, F. Li, The crosstalk between Target of Rapamycin (TOR) and Jasmonic Acid (JA) signaling existing in Arabidopsis and cotton, Sci. Rep. 7 (2017) 45830, https://doi.org/10.1038/srep45830.

[86] P. Wang, Y. Zhao, Z. Li, C.-C. Hsu, X. Liu, L. Fu, Y.-J. Hou, Y. Du, S. Xie, C. Zhang, J. Gao, M. Cao, X. Huang, Y. Zhu, K. Tang, X. Wang, W.A. Tao, Y. Xiong, J.-K. Zhu, Reciprocal regulation of the TOR kinase and ABA receptor balances plant growth and stress response, Mol. Cell 69 (2018) 100-112, https://doi.org/10.1016/j. molcel.2017.12.002 e6.

[87] A. Kravchenko, S. Citerne, I. Jéhanno, R.I. Bersimbaev, B. Veit, C. Meyer, A.S. Leprince, Mutations in the Arabidopsis Lst8 and Raptor genes encoding partners of the TOR complex, or inhibition of TOR activity decrease abscisic acid (ABA) synthesis, Biochem. Biophys. Res. Commun. 467 (2015) 992-997, https://doi.org/ 10.1016/j.bbrc.2015.10.028

[88] P. Punzo, A. Ruggiero, M. Possenti, R. Nurcato, A. Costa, G. Morelli, S. Grillo, G. Batelli, The PP2A-interactor TIP41 modulates ABA responses in Arabidopsis thaliana, Plant J. 94 (2018) 991-1009, https://doi.org/10.1111/tpj.13913.

[89] R. Waadt, B. Manalansan, N. Rauniyar, S. Munemasa, M.A. Booker, B. Brandt, C. Waadt, D.A. Nusinow, S.A. Kay, H.-H. Kunz, K. Schumacher, A. DeLong J.R. Yates, J.I. Schroeder, Identification of open Stomata1-Interacting proteins reveals interactions with sucrose Non-fermenting1-Related protein Kinases2 and with type $2 \mathrm{~A}$ protein phosphatases that function in abscisic acid responses, Plant Physiol. 169 (2015) 760-779, https://doi.org/10.1104/pp.15.00575.

[90] D. Deprost, L. Yao, R. Sormani, M. Moreau, G. Leterreux, M. Nicolaï, M. Bedu, C. Robaglia, C. Meyer, The Arabidopsis TOR kinase links plant growth, yield, stress resistance and mRNA translation, EMBO Rep. 8 (2007) 864-870, https://doi.org/ 10.1038/sj.embor.7401043.

[91] M. Ren, P. Venglat, S. Qiu, L. Feng, Y. Cao, E. Wang, D. Xiang, J. Wang, D. Alexander, S. Chalivendra, D. Logan, A. Mattoo, G. Selvaraj, R. Datla, Target of rapamycin signaling regulates metabolism, growth, and life span in Arabidopsis, 
Plant Cell 24 (2012) 4850-4874, https://doi.org/10.1105/tpc.112.107144.

92] C. Caldana, Y. Li, A. Leisse, Y. Zhang, L. Bartholomaeus, A.R. Fernie, L. Willmitzer, P. Giavalisco, Systemic analysis of inducible target of rapamycin mutants reveal a general metabolic switch controlling growth in Arabidopsis thaliana, Plant J. 73 (2013) 897-909, https://doi.org/10.1111/tpj.12080.

[93] L. Wang, H. Li, C. Zhao, S. Li, L. Kong, W. Wu, W. Kong, Y. Liu, Y. Wei, J.-K. Zhu, H. Zhang, The inhibition of protein translation mediated by AtGCN1 is essential for cold tolerance in Arabidopsis thaliana: AtGCN1 is essential for cold tolerance, Plant Cell Environ. 40 (2017) 56-68, https://doi.org/10.1111/pce.12826.

[94] S. Dong, A.A. Teleman, C. Jedmowski, M. Wirtz, R. Hell, The ArabidopsisTHADA homologue modulates TOR activity and cold acclimation, Plant Biol. 21 (2018) 77-83, https://doi.org/10.1111/plb.12893.

[95] D. Allen, J. Seo, ER stress activates the TOR pathway through Atf6, J. Mol. Signal. 13 (2018) 1, https://doi.org/10.5334/1750-2187-13-1.

[96] D. Kwak, S. Choi, H. Jeong, J.-H. Jang, Y. Lee, H. Jeon, M.N. Lee, J. Noh, K. Cho, J.S. Yoo, D. Hwang, P.-G. Suh, S.H. Ryu, Osmotic stress regulates mTOR complex 1 via JNK-mediated Raptor phosphorylation, J. Biol. Chem. (2012), https://doi.org/ 10.1074/jbc.M111.326538 jbc.M111.326538.

[97] L.-V. Meteignier, M. El Oirdi, M. Cohen, T. Barff, D. Matteau, J.-F. Lucier, S. Rodrigue, P.-E. Jacques, K. Yoshioka, P. Moffett, Translatome analysis of an NBLRR immune response identifies important contributors to plant immunity in Arabidopsis, J. Exp. Bot. 68 (2017) 2333-2344, https://doi.org/10.1093/jxb/ erx078.

[98] N.R. Aznar, V.F. Consolo, G.L. Salerno, G.M.A. Martínez-Noël, TOR signaling downregulation increases resistance to the cereal killer Fusarium graminearum, Plant Signal. Behav. 13 (2018) e1414120, , https://doi.org/10.1080/15592324 2017.1414120.

[99] D. De Vleesschauwer, O. Filipe, G. Hoffman, H.S. Seifi, A. Haeck, P. Canlas, J. Van Bockhaven, E. De Waele, K. Demeestere, P. Ronald, M. Hofte, Target of rapamycin signaling orchestrates growth-defense trade-offs in plants, New Phytol. 217 (2018) 305-319, https://doi.org/10.1111/nph.14785.

[100] G.M.A. Martínez-Noël, J.A. Tognetti, Chapter 22 - sugar signaling under abiotic stress in plants, in: P. Ahmad, M.A. Ahanger, V.P. Singh, D.K. Tripathi, P. Alam, M.N. Alyemeni (Eds.), Plant Metabolites and Regulation Under Environmental Stress, Academic Press, 2018, pp. 397-406, , https://doi.org/10.1016/B978-0-12812689-9.00022-4

[101] S. Signorelli, Ł.P. Tarkowski, W. Van den Ende, D.C. Bassham, Linking autophagy to abiotic and biotic stress responses, Trends Plant Sci. (2019), https://doi.org/10. 1016/j.tplants.2019.02.001

[102] K. Yokawa, F. Baluška, The TOR complex: an emergency switch for root behavior, Plant Cell Physiol. 57 (2016) 14-18, https://doi.org/10.1093/pcp/pcv191.

[103] F.K. Choudhury, R.M. Rivero, E. Blumwald, R. Mittler, Reactive oxygen species, abiotic stress and stress combination, Plant J. 90 (2017) 856-867, https://doi.org/ $10.1111 /$ tpj.13299.

[104] M. Rodríguez, N. Muñoz, S. Lenardon, R. Lascano, Redox-related metabolites and gene expression modulated by sugar in sunflower leaves: similarities with Sunflower chlorotic mottle virus-induced symptom, Redox Rep. 18 (2013) 27-35, https://doi.org/10.1179/1351000212Y.0000000035.

[105] G. Noctor, A. Mhamdi, S. Chaouch, Y. Han, J. Neukermans, B. Marquez-Garcia, G. Queval, C.H. Foyer, Glutathione in plants: an integrated overview: glutathione status and functions, Plant, Cell \& Environment. 35 (2012) 454-484, https://doi. org/10.1111/j.1365-3040.2011.02400.x.

[106] A. Speiser, M. Silbermann, Y. Dong, S. Haberland, V.V. Uslu, S. Wang, S.A.K. Bangash, M. Reichelt, A.J. Meyer, M. Wirtz, R. Hell, Sulfur partitioning between glutathione and protein synthesis determines plant growth, Plant Physiol. 177 (2018) 927-937, https://doi.org/10.1104/pp.18.00421.

[107] N.G. Halford, S. Hey, D. Jhurreea, S. Laurie, R.S. McKibbin, M. Paul, Y. Zhang, Metabolic signalling and carbon partitioning: role of Snf1-related (SnRK1) protein kinase, J. Exp. Bot. 54 (2003) 467-475, https://doi.org/10.1093/jxb/erg038.

[108] S. Hulsmans, M. Rodriguez, B. De Coninck, F. Rolland, The SnRK1 energy sensor in plant biotic interactions, Trends Plant Sci. 21 (2016) 648-661, https://doi.org/10. 1016/j.tplants. 2016.04.008.

[109] M. Ramon, P. Ruelens, Y. Li, J. Sheen, K. Geuten, F. Rolland, The hybrid Four-CBSDomain KIN $\beta \gamma$ subunit functions as the canonical $\gamma$ subunit of the plant energy sensor SnRK1, Plant J. 75 (2013) 11-25, https://doi.org/10.1111/tpj.12192.

[110] L.E. O'Hara, M.J. Paul, A. Wingler, How do sugars regulate plant growth and development? New insight into the role of Trehalose-6-Phosphate, Mol. Plant 6 (2013) 261-274, https://doi.org/10.1093/mp/sss120.

[111] C.A. Griffiths, R. Sagar, Y. Geng, L.F. Primavesi, M.K. Patel, M.K. Passarelli, I.S. Gilmore, R.T. Steven, J. Bunch, M.J. Paul, B.G. Davis, Chemical intervention in plant sugar signalling increases yield and resilience, Nature. 540 (2016) 574-578, https://doi.org/10.1038/nature20591.

[112] E. Baena-González, Energy signaling in the regulation of gene expression during stress, Mol. Plant 3 (2010) 300-313, https://doi.org/10.1093/mp/ssp113.

[113] M. Jossier, J.-P. Bouly, P. Meimoun, A. Arjmand, P. Lessard, S. Hawley, D. Grahame Hardie, M. Thomas, SnRK1 (SNF1-related kinase 1) has a central role in sugar and ABA signalling in Arabidopsis thaliana, Plant J. 59 (2009) 316-328, https://doi.org/10.1111/j.1365-313X.2009.03871.x.

[114] C. Polge, M. Thomas, SNF1/AMPK/SnRK1 kinases, global regulators at the heart of energy control? Trends Plant Sci. 12 (2007) 20-28, https://doi.org/10.1016/j. tplants.2006.11.005.

[115] P. Crozet, L. Margalha, A. Confraria, A. Rodrigues, C. Martinho, M. Adamo, C.A. Elias, E. Baena-González, Mechanisms of regulation of SNF1/AMPK/SnRK1 protein kinases, Front. Plant Sci. 5 (2014), https://doi.org/10.3389/fpls.2014 00190.

[116] W. Shen, L. Hanley-Bowdoin, Geminivirus infection up-regulates the expression of two Arabidopsis protein kinases related to yeast SNF1- and mammalian AMPKActivating kinases, Plant Physiol. 142 (2006) 1642-1655, https://doi.org/10. 1104/pp.106.088476.

[117] W. Shen, M.I. Reyes, L. Hanley-Bowdoin, Arabidopsis protein kinases GRIK1 and GRIK2 specifically activate SnRK1 by phosphorylating its activation loop, Plant Physiol. 150 (2009) 996-1005, https://doi.org/10.1104/pp.108.132787.

[118] J. de, D. Barajas-Lopez, J.R. Moreno, F.M. Gamez-Arjona, J.M. Pardo, M. Punkkinen, J.-K. Zhu, F.J. Quintero, H. Fujii, Upstream kinases of plant SnRKs are involved in salt stress tolerance, Plant J. 93 (2018) 107-118, https://doi.org/ $10.1111 /$ tpj.13761.

[119] K.-W. Lee, P.-W. Chen, C.-A. Lu, S. Chen, T.-H.D. Ho, S.-M. Yu, Coordinated responses to oxygen and sugar deficiency allow rice seedlings to tolerate flooding, Sci. Signal. 2 (2009), https://doi.org/10.1126/scisignal.2000333 ra61-ra61.

[120] J. Avila, O.G. Gregory, D. Su, T.A. Deeter, S. Chen, C. Silva-Sanchez, S. Xu, G.B. Martin, T.P. Devarenne, The -Subunit of the SnRK1 complex is phosphorylated by the plant cell death suppressor Adi3, Plant Physiol. 159 (2012) 1277-1290, https://doi.org/10.1104/pp.112.198432.

[121] A. Rodrigues, M. Adamo, P. Crozet, L. Margalha, A. Confraria, C. Martinho, A. Elias, A. Rabissi, V. Lumbreras, M. González-Guzmán, R. Antoni, P.L. Rodriguez, E. Baena-González, ABI1 and PP2CA phosphatases are negative regulators of Snf1-related protein kinase1 signaling in Arabidopsis, Plant Cell 25 (2013) 3871-3884, https://doi.org/10.1105/tpc.113.114066.

[122] C. Sugden, R.M. Crawford, N.G. Halford, D.G. Hardie, Regulation of spinach SNF1 related (SnRK1) kinases by protein kinases and phosphatases is associated with phosphorylation of the T loop and is regulated by 5'-AMP, Plant J. 19 (1999) 433-439.

[123] C.-R. Lin, K.-W. Lee, C.-Y. Chen, Y.-F. Hong, J.-L. Chen, C.-A. Lu, K.-T. Chen, T.H.D. Ho, S.-M. Yu, SnRK1A-Interacting Negative Regulators modulate the nutrient starvation signaling sensor SnRK1 in source-sink communication in cereal seedlings under abiotic stress, Plant Cell 26 (2014) 808-827, https://doi.org/10.1105/ tpc.113.121939.

[124] R.P. Bhalerao, K. Salchert, L. Bakó, L. Okrész, L. Szabados, T. Muranaka, Y. Machida, J. Schell, C. Koncz, Regulatory interaction of PRL1 WD protein with Arabidopsis SNF1-like protein kinases, Proc. Natl. Acad. Sci. U.S.A. 96 (1999) 5322-5327.

[125] M. Pierre, J.A. Traverso, B. Boisson, S. Domenichini, D. Bouchez, C. Giglione, T. Meinnel, N-myristoylation regulates the SnRK1 pathway in Arabidopsis, THE PLANT CELL ONLINE. 19 (2007) 2804-2821, https://doi.org/10.1105/tpc.107. 051870 .

[126] P. Crozet, L. Margalha, R. Butowt, N. Fernandes, C.A. Elias, B. Orosa, K. Tomanov, M. Teige, A. Bachmair, A. Sadanandom, E. Baena-González, SUMOylation represses SnRK1 signaling in Arabidopsis, Plant J. 85 (2016) 120-133, https://doi. org/10.1111/tpj.13096.

[127] M. Jamsheer K, D. Singh, M. Sharma, M. Sharma, S. Jindal, C.T. Mannully, B.N. Shukla, A. Laxmi, The FCS-LIKE ZINC FINGER 6 and 10 are involved in regulating osmotic stress responses in Arabidopsis, Plant Signal. Behav. (2019) 1-4, https://doi.org/10.1080/15592324.2019.1592535.

[128] C. Nunes, L.F. Primavesi, M.K. Patel, E. Martinez-Barajas, S.J. Powers, R. Sagar, P.S. Fevereiro, B.G. Davis, M.J. Paul, Inhibition of SnRK1 by metabolites: tissuedependent effects and cooperative inhibition by glucose 1-phosphate in combination with trehalose 6-phosphate, Plant Physiol. Biochem. 63 (2013) 89-98, https://doi.org/10.1016/j.plaphy.2012.11.011.

[129] Y. Zhang, L.F. Primavesi, D. Jhurreea, P.J. Andralojc, R.A.C. Mitchell, S.J. Powers, H. Schluepmann, T. Delatte, A. Wingler, M.J. Paul, dprotein kinase1 activity and regulation of metabolic pathways by trehalose-6-phosphate, Plant Physiol. 149 (2009) 1860-1871, https://doi.org/10.1104/pp.108.133934.

[130] Z. Zhai, J. Keereetaweep, H. Liu, R. Feil, J.E. Lunn, J. Shanklin, Trehalose 6Phosphate positively regulates fatty acid synthesis by stabilizing WRINKLED1, Plant Cell 30 (2018) 2616-2627, https://doi.org/10.1105/tpc.18.00521.

[131] T.E. Scarpeci, E.M. Valle, Rearrangement of carbon metabolism in Arabidopsis thaliana subjected to oxidative stress condition: an emergency survival strategy, Plant Growth Regul. 54 (2008) 133-142, https://doi.org/10.1007/s10725-0079236-5.

[132] B. Wurzinger, A. Mair, K. Fischer-Schrader, E. Nukarinen, V. Roustan, W. Weckwerth, M. Teige, Redox state-dependent modulation of plant SnRK1 kinase activity differs from AMPK regulation in animals, FEBS Lett. 591 (2017) 3625-3636, https://doi.org/10.1002/1873-3468.12852.

[133] B. Wurzinger, E. Nukarinen, T. Nägele, W. Weckwerth, M. Teige, The SnRK1 kinase as central mediator of energy signaling between different organelles, Plant Physiol. 176 (2018) 1085-1094, https://doi.org/10.1104/pp.17.01404.

[134] K.-J. Dietz, C. Wesemann, M. Wegener, T. Seidel, Toward an integrated under standing of retrograde control of photosynthesis, Antioxid. Redox Signal. 30 (2019) 1186-1205, https://doi.org/10.1089/ars.2018.7519.

[135] A.Y.-L. Tsai, S. Gazzarrini, Trehalose-6-phosphate and SnRK1 kinases in plant development and signaling: the emerging picture, Front. Plant Sci. 5 (2014) 119, https://doi.org/10.3389/fpls.2014.00119.

[136] A.Y.-L. Tsai, S. Gazzarrini, AKIN10 and FUSCA3 interact to control lateral organ development and phase transitions in Arabidopsis, Plant J. 69 (2012) 809-821, https://doi.org/10.1111/j.1365-313X.2011.04832.x.

[137] J.H. Im, Y.-H. Cho, G.-D. Kim, G.-H. Kang, J.-W. Hong, S.-D. Yoo, Inverse modulation of the energy sensor Snf1-related protein kinase 1 on hypoxia adaptation and salt stress tolerance in A rabidopsis thaliana: salt stress and hypoxia signalling in Arabidopsis, Plant Cell Environ. (2014), https://doi.org/10.1111/pce.12375 n/ a-n/a..

[138] A. Mair, L. Pedrotti, B. Wurzinger, D. Anrather, A. Simeunovic, C. Weiste, C. Valerio, K. Dietrich, T. Kirchler, T. Nägele, J. Vicente Carbajosa, J. Hanson, 
E. Baena-González, C. Chaban, W. Weckwerth, W. Dröge-Laser, M. Teige, SnRK1triggered switch of bZIP63 dimerization mediates the low-energy response in plants, ELife. 4 (2015), https://doi.org/10.7554/eLife.05828.

[139] P. Garapati, R. Feil, J.E. Lunn, P.V. Dijck, S. Balazadeh, B. Mueller-Roeber, Transcription factor Arabidopsis Activating Factor1 integrates carbon starvation responses with trehalose metabolism, Plant Physiol. 169 (2015) 379-390, https:// doi.org/10.1104/pp.15.00917.

[140] E.-Y. Jeong, P.J. Seo, J.C. Woo, C.-M. Park, AKIN10 delays flowering by in activating IDD8 transcription factor through protein phosphorylation in Arabidopsis, BMC Plant Biol. 15 (2015), https://doi.org/10.1186/s12870-015 0503-8.

[141] C. Yu, L. Song, J. Song, B. Ouyang, L. Guo, L. Shang, T. Wang, H. Li, J. Zhang, Z. Ye, ShCIGT, a Trihelix family gene, mediates cold and drought tolerance by interacting with SnRK1 in tomato, Plant Sci. 270 (2018) 140-149, https://doi.org/ 10.1016/j.plantsci.2018.02.012.

[142] P.R. Clarke, D.G. Hardie, Regulation of HMG-CoA reductase: identification of the site phosphorylated by the AMP-activated protein kinase in vitro and in intact rat liver, EMBO J. 9 (1990) 2439-2446, https://doi.org/10.1002/j.1460-2075.1990. tb07420.x.

[143] R.W. Mackintosh, S.P. Davies, P. R. Clarke, J. Weekes, J.G. Gillespie, B.J. Gibb, D.G. Hardie, Evidence for a protein kinase cascade in higher plants. 3-Hydroxy-3methylglutaryl-CoA reductase kinase, Eur. J. Biochem. 209 (1992) 923-931.

[144] L. Wang, Y.-L. Ruan, Regulation of cell division and expansion by sugar and auxin signaling, Front. Plant Sci. 4 (2013), https://doi.org/10.3389/fpls.2013.00163.

[145] S. Ng, E. Giraud, O. Duncan, S.R. Law, Y. Wang, L. Xu, R. Narsai, C. Carrie, H. Walker, D.A. Day, N.E. Blanco, A. Strand, J. Whelan, A. Ivanova, Cyclin-dependent kinase E1 (CDKE1) provides a cellular switch in plants between growth and stress responses, J. Biol. Chem. 288 (2013) 3449-3459, https://doi.org/10. 1074/jbc.M112.416727.

[146] N.E. Blanco, M. Guinea-Díaz, J. Whelan, Åsa Strand, Interaction between plastid and mitochondrial retrograde signalling pathways during changes to plastid redox status, Philos. Trans. Biol. Sci. 369 (2014) 20130231, , https://doi.org/10.1098/ rstb.2013.0231.

[147] S. Wagner, O. Van Aken, M. Elsässer, M. Schwarzländer, Mitochondrial energy signaling and its role in the low-oxygen stress response of plants, Plant Physiol. 176 (2018) 1156-1170, https://doi.org/10.1104/pp.17.01387.

[148] P. Douglas, E. Pigaglio, A. Ferrer, N.G. Halfords, C. MacKintosh, Three spinach leaf nitrate reductase-3-hydroxy-3-methylglutaryl-CoA reductase kinases that are regulated by reversible phosphorylation and/or Ca2 + ions, Biochem. J. 325 (Pt 1) (1997) 101-109.

[149] E. Nukarinen, T. Nägele, L. Pedrotti, B. Wurzinger, A. Mair, R. Landgraf, F. Börnke, J. Hanson, M. Teige, E. Baena-Gonzalez, W. Dröge-Laser, W. Weckwerth, Quantitative phosphoproteomics reveals the role of the AMPK plant ortholog SnRK1 as a metabolic master regulator under energy deprivation, Sci. Rep. 6 (2016) 31697, https://doi.org/10.1038/srep31697.

[150] C. Weiste, L. Pedrotti, J. Selvanayagam, P. Muralidhara, C. Fröschel, O. Novák, K. Ljung, J. Hanson, W. Dröge-Laser, The Arabidopsis bZIP11 transcription factor links low-energy signalling to auxin-mediated control of primary root growth, PLoS Genet. 13 (2017) e1006607, , https://doi.org/10.1371/journal.pgen. 1006607.

[151] S. Gazzarrini, Y. Tsuchiya, S. Lumba, M. Okamoto, P. McCourt, The transcription factor FUSCA3 controls developmental timing in Arabidopsis through the hormones gibberellin and abscisic acid, Dev. Cell 7 (2004) 373-385, https://doi.org/ 10.1016/j.devcel.2004.06.017.

[152] J. Curaba, AtGA3ox2, a Key Gene Responsible for Bioactive Gibberellin Biosynthesis, Is Regulated during Embryogenesis by LEAFY COTYLEDON2 and FUSCA3 in Arabidopsis, Plant Physiol. 136 (2004) 3660-3669, https://doi.org/10. 1104/pp.104.047266.

[153] Y. Wang, J. Zhao, W. Lu, D. Deng, Gibberellin in plant height control: old player, new story, Plant Cell Rep. 36 (2017) 391-398, https://doi.org/10.1007/s00299017-2104-5.

[154] X. Hou, W.-W. Hu, L. Shen, L.Y.C. Lee, Z. Tao, J.-H. Han, H. Yu, Global identification of DELLA target genes during Arabidopsis flower development, Plant Physiol. 147 (2008) 1126-1142, https://doi.org/10.1104/pp.108.121301.

[155] M. Nietzsche, R. Landgraf, T. Tohge, F. Börnke, A protein-protein interaction network linking the energy-sensor kinase SnRK1 to multiple signaling pathways in Arabidopsis thaliana, Curr. Plant Biol. 5 (2016) 36-44, https://doi.org/10.1016/j. cpb.2015.10.004.

[156] X.-J. Liu, X. Liu, X.-H. An, P.-L. Han, C.-X. You, Y.-J. Hao, An apple protein kinase MdSnRK1.1 interacts with MdCAIP1 to regulate ABA sensitivity, Plant Cell Physiol. 58 (2017) 1631-1641, https://doi.org/10.1093/pcp/pcx096.

[157] G.-D. Kim, Y.-H. Cho, S.-D. Yoo, Regulatory functions of cellular energy sensor SNF1-Related Kinase1 for leaf senescence delay through ETHYLENEINSENSITIVE3 repression, Sci. Rep. 7 (2017) 3193, https://doi.org/10.1038/ s41598-017-03506-1.

[158] G.-D. Kim, Y.-H. Cho, S.-D. Yoo, Phytohormone ethylene-responsive Arabidopsis organ growth under light is in the fine regulation of Photosystem II deficiencyinducible AKIN10 expression, Sci. Rep. 7 (2017), https://doi.org/10.1038/ s41598-017-02897-5.

[159] X.-J. Liu, X.-H. An, X. Liu, D.-G. Hu, X.-F. Wang, C.-X. You, Y.-J. Hao, MdSnRK1.1 interacts with MdJAZ18 to regulate sucrose-induced anthocyanin and proanthocyanidin accumulation in apple, J. Exp. Bot. 68 (2017) 2977-2990, https://doi org $/ 10.1093 / \mathrm{jxb} / \mathrm{erx} 150$.

[160] H.-Y. Cho, T.-N. Wen, Y.-T. Wang, M.-C. Shih, Quantitative phosphoproteomics of protein kinase SnRK1 regulated protein phosphorylation in Arabidopsis under submergence, J. Exp. Bot. 67 (2016) 2745-2760, https://doi.org/10.1093/jxb/ erw107.

[161] H. Cho, M.J. Lu, M. Shih, The SnRK1-eIFiso4G1 signaling relay regulates the translation of specific mRNAs in Arabidopsis under submergence, New Phytol. (2018), https://doi.org/10.1111/nph.15589.

[162] A. Soltani, S. MafiMoghaddam, A. Oladzad-Abbasabadi, K. Walter, P.J. Kearns, J. Vasquez-Guzman, S. Mamidi, R. Lee, A.L. Shade, J.L. Jacobs, M.I. Chilivers, D.B. Lowry, P. McClean, J.M. Osorno, Genetic analysis of flooding tolerance in an andean diversity panel of dry bean (Phaseolus vulgaris L.), Front. Plant Sci. 9 (2018), https://doi.org/10.3389/fpls.2018.00767.

[163] L. Chen, Z.-Z. Su, L. Huang, F.-N. Xia, H. Qi, L.-J. Xie, S. Xiao, Q.-F. Chen, The AMP-Activated protein kinase KIN10 is involved in the regulation of autophagy in Arabidopsis, Front. Plant Sci. 8 (2017), https://doi.org/10.3389/fpls.2017.01201.

[164] Y. Xiong, A.L. Contento, P.Q. Nguyen, D.C. Bassham, Degradation of oxidized proteins by autophagy during oxidative stress in Arabidopsis, Plant Physiol. 143 (2007) 291-299, https://doi.org/10.1104/pp.106.092106.

[165] M.E. Perez-Perez, S.D. Lemaire, J.L. Crespo, Reactive oxygen species and autophagy in plants and algae, Plant Physiol. 160 (2012) 156-164, https://doi.org/10. 1104/pp.112.199992.

[166] A. Lovas, A. Bimbo, L. Szabo, Z. Banfalvi, Antisense repression of StubGAL83 affects root and tuber development in potato, Plant J. 33 (2003) 139-147, https:// doi.org/10.1046/j.1365-313X.2003.016015.x.

[167] J. Buitink, M. Thomas, L. Gissot, O. Leprince, Starvation, osmotic stress and desiccation tolerance lead to expression of different genes of the regulatory beta and gamma subunits of the SnRK1 complex in germinating seeds of Medicago truncatula, Plant, Cell and Environment. 27 (2004) 55-67, https://doi.org/10.1046/j. 0016-8025.2003.01125.x.

[168] M. Nietzsche, I. Schießl, F. Börnke, The complex becomes more complex: proteinprotein interactions of SnRK1 with DUF581 family proteins provide a framework for cell- and stimulus type-specific SnRK1 signaling in plants, Front. Plant Sci. 5 (2014) 54, https://doi.org/10.3389/fpls.2014.00054.

[169] T. Dobrenel, C. Marchive, M. Azzopardi, G. Clément, M. Moreau, R. Sormani, C. Robaglia, C. Meyer, Sugar metabolism and the plant target of rapamycin kinase: a sweet operaTOR? Front. Plant Sci. 4 (2013), https://doi.org/10.3389/fpls.2013. 00093.

[170] R. Valluru, W. Van den Ende, Myo-inositol and beyond - emerging networks under stress, Plant Sci. 181 (2011) 387-400, https://doi.org/10.1016/j.plantsci.2011. 07.009 .

[171] W. Van den Ende, Multifunctional fructans and raffinose family oligosaccharides, Front. Plant Sci. 4 (2013), https://doi.org/10.3389/fpls.2013.00247.

[172] L. Hartmann, L. Pedrotti, C. Weiste, A. Fekete, J. Schierstaedt, J. Göttler, S. Kempa, M. Krischke, K. Dietrich, M.J. Mueller, J. Vicente-Carbajosa, J. Hanson, W. DrögeLaser, Crosstalk between two bZIP signaling pathways orchestrates salt-induced metabolic reprogramming in Arabidopsis roots, Plant Cell 27 (2015) 2244-2260 https://doi.org/10.1105/tpc.15.00163.

[173] J. Ma, M. Hanssen, K. Lundgren, L. Hernández, T. Delatte, A. Ehlert, C.-M. Liu, H. Schluepmann, W. Dröge-Laser, T. Moritz, S. Smeekens, J. Hanson, The sucroseregulated Arabidopsis transcription factor bZIP11 reprograms metabolism and regulates trehalose metabolism, New Phytol. 191 (2011) 733-745, https://doi. org/10.1111/j.1469-8137.2011.03735.x.

[174] U. Bechtold, B. Field, Molecular mechanisms controlling plant growth during abiotic stress, J. Exp. Bot. 69 (2018) 2753-2758, https://doi.org/10.1093/jxb/ ery157.

[175] G.R. Cramer, K. Urano, S. Delrot, M. Pezzotti, K. Shinozaki, Effects of abiotic stress on plants: a systems biology perspective, BMC Plant Biol. 11 (2011) 163, https:// doi.org/10.1186/1471-2229-11-163.

[176] J. Kim, Sugar metabolism as input signals and fuel for leaf senescence, Genes Genomics (2019), https://doi.org/10.1007/s13258-019-00804-y.

[177] A. Lloret, A. Conejero, C. Leida, C. Petri, F. Gil-Muñoz, L. Burgos, M.L. Badenes, G. Ríos, Dual regulation of water retention and cell growth by a stress-associated protein (SAP) gene in Prunus, Sci. Rep. 7 (2017) 332, https://doi.org/10.1038/ s41598-017-00471-7.

[178] M.A. Salem, Y. Li, A. Wiszniewski, P. Giavalisco, Regulatory-associated protein of TOR (RAPTOR) alters the hormonal and metabolic composition of Arabidopsis seeds, controlling seed morphology, viability and germination potential, Plant $\mathrm{J}$. 92 (2017) 525-545, https://doi.org/10.1111/tpj.13667.

[179] K. Wang, Y. Liu, J. Tian, K. Huang, T. Shi, X. Dai, W. Zhang, Transcriptional profiling and identification of heat-responsive genes in perennial ryegrass by RNASequencing, Front. Plant Sci. 8 (2017) 1032, https://doi.org/10.3389/fpls.2017. 01032.

[180] S.E. Atwood, J.A. O'Rourke, G.A. Peiffer, T. Yin, M. Majumder, C. Zhang, S.R. Cianzio, J.H. Hill, D. Cook, S.A. Whitham, R.C. Shoemaker, M.A. Graham, Replication protein A subunit 3 and the iron efficiency response in soybean, Plant Cell Environ. 37 (2014) 213-234, https://doi.org/10.1111/pce.12147.

[181] J. Soto-Burgos, D.C. Bassham, SnRK1 activates autophagy via the TOR signaling pathway in Arabidopsis thaliana, PLoS One 12 (2017) e0182591, , https://doi. org/10.1371/journal.pone.0182591.

[182] M. Jamsheer K, A. Laxmi, Expression of Arabidopsis FCS-Like Zinc finger genes is differentially regulated by sugars, cellular energy level, and abiotic stress, Front. Plant Sci. 6 (2015) 746, https://doi.org/10.3389/fpls.2015.00746.

[183] M. Oszvald, L.F. Primavesi, C.A. Griffiths, J. Cohn, S.S. Basu, M.L. Nuccio, M.J. Paul, Trehalose 6-Phosphate regulates photosynthesis and assimilate partitioning in reproductive tissue, Plant Physiol. 176 (2018) 2623-2638, https://doi. org $/ 10.1104 / \mathrm{pp} .17 .01673$.

[184] M.A. Asensi-Fabado, A. Ammon, U. Sonnewald, S. Munné-Bosch, L.M. Voll, Tocopherol deficiency reduces sucrose export from salt-stressed potato leaves independently of oxidative stress and symplastic obstruction by callose, J. Exp. Bot. 
66 (2015) 957-971, https://doi.org/10.1093/jxb/eru453.

[185] T.L. Delatte, P. Sedijani, Y. Kondou, M. Matsui, G.J. de Jong, G.W. Somsen, A. Wiese-Klinkenberg, L.F. Primavesi, M.J. Paul, H. Schluepmann, Growth arrest by trehalose-6-phosphate: an astonishing case of primary metabolite control over growth by way of the SnRK1 signaling pathway, Plant Physiol. 157 (2011) 160-174, https://doi.org/10.1104/pp.111.180422.

[186] L. Pedrotti, C. Weiste, T. Nägele, E. Wolf, F. Lorenzin, K. Dietrich, A. Mair, W. Weckwerth, M. Teige, E. Baena-González, W. Dröge-Laser, Snf1-RELATED KINASE1-Controlled C/S1-bZIP signaling activates alternative mitochondrial metabolic pathways to ensure plant survival in extended darkness, Plant Cell 30 (2018) 495-509, https://doi.org/10.1105/tpc.17.00414.

[187] O. Thimm, O. Bläsing, Y. Gibon, A. Nagel, S. Meyer, P. Krüger, J. Selbig, L.A. Müller, S.Y. Rhee, M. Stitt, Mapman: a user-driven tool to display genomics data sets onto diagrams of metabolic pathways and other biological processes, Plant J. 37 (2004) 914-939, https://doi.org/10.1111/j.1365-313X.2004.02016.x.

[188] M. Durgud, S. Gupta, I. Ivanov, M.A. Omidbakhshfard, M. Benina, S. Alseekh, N. Staykov, M. Hauenstein, P.P. Dijkwel, S. Hörtensteiner, V. Toneva, Y. Brotman, A.R. Fernie, B. Mueller-Roeber, T.S. Gechev, Molecular Mechanisms Preventing Senescence in Response to Prolonged Darkness in a Desiccation-Tolerant Plant, Plant Physiol. 177 (2018) 1319-1338, https://doi.org/10.1104/pp.18.00055.
[189] E.A. Ananieva, G.E. Gillaspy, A. Ely, R.N. Burnette, F.L. Erickson, Interaction of the WD40 domain of a myoinositol polyphosphate 5-phosphatase with SnRK1 links inositol, sugar, and stress signaling, Plant Physiol. 148 (2008) 1868-1882, https:// doi.org/10.1104/pp.108.130575.

[190] S. Fragoso, L. Espindola, J. Paez-Valencia, A. Gamboa, Y. Camacho, E. MartinezBarajas, P. Coello, SnRK1 Isoforms AKIN10 and AKIN11 Are Differentially Regulated in Arabidopsis Plants under Phosphate Starvation, Plant Physiol. 149 (2009) 1906-1916, https://doi.org/10.1104/pp.108.133298.

[191] S.W. Bledsoe, C. Henry, C.A. Griffiths, M.J. Paul, R. Feil, J.E. Lunn, M. Stitt, L.M. Lagrimini, The role of Tre6P and SnRK1 in maize early kernel development and events leading to stress-induced kernel abortion, BMC Plant Biol. 17 (2017) 74, https://doi.org/10.1186/s12870-017-1018-2.

[192] P. Coello, E. Martínez-Barajas, The activity of SnRK1 is increased in Phaseolus vulgaris seeds in response to a reduced nutrient supply, Front. Plant Sci. 5 (2014) 196, https://doi.org/10.3389/fpls.2014.00196.

[193] P. Coello, E. Martínez-Barajas, Changes in nutrient distribution are part of the mechanism that promotes seed development under severe nutrient restriction, Plant Physiol, Biochem. 99 (2016) 21-26, https://doi.org/10.1016/j.plaphy.2015. 11.022 